\title{
Snapshot of narcotic drugs and psychoactive substances in Kuwait: a qualitative analysis of illicit drugs and their associated mortality in Kuwait from 2015 to 2018
}

Abdullah Al-Matrouk ( $\sim$ akalmatrouk@moi.gov.kw )

University of Interior Kuwait

Mohammed Al-Hasan

Ministry of Interior, Farwaniya City

Neamat Al-Abkal

Ministry of Interior, Farwaniya City

Hanan Mohammed

Ministry of Interior, Farwaniya City

Meshaal Haider

Ministry of Interior, Farwaniya City

Dalal Al-Shammeri

Ministry of Interior, Farwaniya City

Haider Bojbarah

Ministry of Interior, Farwaniya City

Research article

Keywords: MENA, Kuwait, GC-MS, LC-MS-MS, illicit drugs, psychoactive substances

Posted Date: June 9th, 2020

DOl: https://doi.org/10.21203/rs.3.rs-33143/v1

License: (ㅇ) This work is licensed under a Creative Commons Attribution 4.0 International License. Read Full License

Version of Record: A version of this preprint was published at BMC Public Health on April 7th, 2021. See the published version at https://doi.org/10.1186/s12889-021-10705-z. 


\section{Abstract \\ Background}

The misuse of illicit substances is associated with increased morbidity and mortality; thus, substance abuse is a global health concern. However, a lack of laboratory-based research has limited the scientific assessment of drug misuse in the Arabian Gulf region. Thus, the primary aim of this study was to assess the problem of illicit drugs in Kuwait using laboratory-based analyses.

\section{Methods}

We investigated the type and quantity of detained narcotic drugs and psychotropic substances from 2015 to 2018 , number of abusers, and mortality among abusers. In total, 6220 cases from the Narcotic and Psychotropic Laboratory and 17,755 cases from the Forensic Toxicology Laboratory were reviewed and analyzed. Substances were identified and documented using gas chromatography-mass spectrometry and liquid chromatography-mass spectrometry.

\section{Results}

Cannabis, including marijuana, was the most seized substance, followed by heroin, opium, and cocaine. Amphetamines, including methamphetamine, in the form of powder or pills, were seized in larger quantities than other psychoactive substances. Benzodiazepines, tramadol, Khat, synthetic cannabinoids, and psilocin were also seized. The most consumed substances were, in order, amphetamines (including methamphetamine), benzodiazepines, cannabis, and heroin. Drug misuse was considerably higher among men than among women. We report the death rate associated with the abuse of various illegal drugs according to sex. The mortality rate associated with single-drug use was the highest among abusers of heroin, benzodiazepines, and methamphetamine. The mortality rate asscoaited with multiple-drug use was the highest among abusers of heroin-benzodiazepines, cannabis-benzodiazepines, and cannabisamphetamines.

\section{Conclusions}

Our study shows the changing trends in quantity and variety of substances illegally abused and marketed in Kuwait. Additionally, we report a direct gender-based association between mortality and consumption of certain substances. These findings suggest that there is a growing need to conduct larger scale studies to implement new strategies, policies, and interventions in populations affected by illicit drugs.

\section{Background}


The use of illicit drugs is a global concern. These are highly addictive substances for which extra-medical uses have been prohibited and criminalized under international drug control treaties [1]. Despite international efforts to eliminate drug abuse, the global consumption trend of these substances increases continuously. In 2018, it was estimated that approximately 275 million people ( 5.5\% of world's population) have used illicit substances at least once, which is an increase of $30 \%$ compared with that in $2009[2,3]$. Thus, extra measures are needed to tackle this ongoing crisis.

Illicit substance abuse is a preventable and treatable condition that imposes enormous costs on the global health and economy [4]. The use of these substances carries risks of adverse health outcomes. Drug abuse is accountable for roughly $1.5 \%$ of the global disease burden and was responsible for more than 750,000 premature deaths in 2017 [3]. The use of these substances increases the risks of adverse health conditions, including but not limited to disability, viral infections, sepsis, thrombosis, and endocarditis [5]. Thus, the abuse of illicit drugs adds a severe financial burden on the global economy. The International Narcotics Control Board [6] estimates that the cost of medical care associated with drug misuse is more than $\$ 200$ billion annually. In addition, drug abuse reduces individual productivity, resulting in an estimated loss of tens of billions of dollars from the global economy [6].

The global market for drug trafficking continues to grow each year. The term "drug trafficking" used here refers to cultivation, production, distribution, and sale of illicit substances. In 2017, the United Nations Office on Drugs and Crime (UNODC) estimated that the global market for drug trafficking is worth $\$ 426$ to $\$ 652$ billion [7]. This is the market value derived from sales of the four primary groups of illicit substances: cannabis, cocaine, opiates, and amphetamine-type stimulants. According to the UNODC [7], cannabis sales comprise the largest submarket ( $43-44 \%$ of the total market worth), whereas sales of amphetamine-type stimulants comprise the smallest submarket (14-17\%).

The Middle East and North Africa (MENA) are considered a significant area for illicit substance trafficking. In terms of production, cannabis (Morocco and Lebanon), opiates (Egypt), Khat (Yemen to Somalia), and amphetamine-type stimulants (ATS) (Egypt and Lebanon) are the most produced substances [8]. Owing to its geographical location situated between different trafficking routes and its widespread borders, MENA is recognized as a major transit area for illicit substances. Indeed, MENA links the major drug producers to the vast markets in Europe and the Gulf countries. Illicit substances that flow through MENA include opiates (Golden Crescent to Europe), cannabis (Morocco to the Gulf Countries), cocaine (Latin America to Europe), and amphetamine-type stimulants (Western Africa to Europe) [9]. Because of their importance in drugs trafficking, abuse and addiction in MENA countries are relatively high. As a result, legislative authorities in these countries have imposed harsh penalties for drug-related offences to restrict and reduce the epidemic of recreational use of illicit drugs. However, such legislation only made illegal drug trafficking more lucrative [10].

Despite the importance of this topic, to our knowledge, the few studies published thus far concerning illicit substances that have been seized or consumed, or the associated-death rates, in the Middle East in general, and more specifically in Kuwait, have not been comprehensive [11, 12]. Additionally, most studies that have been previously conducted in Kuwait were outdated survey-based studies that did not rely on solid data 
generated by laboratory-based experiments $[13,14]$. Moreover, the only previous analytical-based study is outdated [15].

A cross-sectional questionnaire conducted on Kuwaiti male students $(n=1587)$ reported that the most commonly used illicit substances were marijuana ( $11 \%)$, stimulants $(7.1 \%)$, cocaine $(2.2 \%)$, and heroin (1.3\%) (13). Omu et al. (2017) performed a survey on illicit drug abuse among teenagers (15 to 18 years) between September 2012 and June 2013 [14]. The results showed that the trend of illegal substances abuse is increasing, especially among older teenagers. Hashish (marijuana) was the most commonly used illicit substance among both current users and previous users, $3.7 \%$ and $5.3 \%$, respectively [14]. A Kuwaiti pilot study confirmed the association between levels of self-esteem and anxiety with drug user behavior [16]. Wilby and Wilbur assessed narcotic requirements in different Arabic-speaking countries in the Middle East region [17]. Bahrain and Kuwait had the highest estimated rate (364 and 352 defined doses per million inhabitants per day, respectively), as well as the highest rates of growth (2008-2012).

Radovanovic et al. assessed the prevalence and trend of different psychoactive substances in Kuwait from 1992 to 1997 by screening 3781 biological samples [15]. According to the study, the most used substances were as follows: cannabinoids, benzodiazepines, opiate, and amphetamine. Other drugs were also identified but at insignificant levels; these included methadone, cocaine, and phencyclidine [15]. However, the information gained in that study was based only on a preliminary analysis (screening tests) of biological samples and is now outdated. Consequently, the current study aimed to identify the types of narcotic drugs and psychotropic substances that were seized and consumed in Kuwait from 2015 to 2018 and their associated mortality. In addition, we identified gender-based differences in substance consumption and their associated deaths.

\section{Methods}

\section{Narcotics and Psychotropic Laboratory (NPL) Procedures}

Receipt of Seized Narcotic Drugs and Psychotropic Substances

Seized narcotic drugs and psychotropic substances were received by the Narcotic and Psychotropic Laboratory (NPL) of Kuwait, a division of the Forensic Laboratories, General Department of Criminal Evidence. NPL is the only accredited laboratory in Kuwait that conducts drug-related investigations and routine drug testing to provide expert opinion (reports) for the court of law.

Seized materials were sent to the NPL by several governmental agencies including the General Directorate of Investigation, the General Directorate for Drug Control, the General Administration of Customs, the General Administration of Correctional Institutions, the Office of Public Prosecutions for Drugs and Alcohol, Juvenile Prosecution, and the Medical Services of the Kuwaiti Army. For quality assurance measures, the receipt of samples by the NPL follows specific procedures. First, sealed samples were received in stamped envelopes by the Quality Control Division to eliminate potential contamination and tampering and to maintain the chain of custody. Next, samples were transferred to the NPL to be registered and analyzed by 
trained forensic science specialists. Finally, results were translated into official reports, which were then forwarded to the appropriate sending department or institute responsible for the samples.

The current study reviews and analyses documented cases that were received by the NPL and the Forensic Toxicology Laboratory (FTL) from January 2015 to December 2018. It also highlights the protocols and the experimental procedures that were used by the laboratory specialists at the NPL to generate the reports. In total, 6,220 cases were acquired and analyzed by NPL between 2015 and 2018. In terms of cases per year, 1,832 cases were received in 2015 ; this decreased in 2016,2017 , and 2018 , to $1,506,1,356$, and 1,526 cases, respectively. Only reports that were generated from cases that were positive for the presence of at least one illicit drug (i.e., those listed in the schedules of narcotic drugs or psychotropic substances) were reviewed and analyzed.

\section{Processing Seized Materials in the NPL}

All procedures were performed according to the required legal provisions and the chain of custody. Regarding the analysis of seized drugs, we followed the recommendations of the Scientific Working Group for the Analysis of Seized Drugs (SWGDRUG) [18]. SWGDRUG is a cooperative effort between the Drug Enforcement Agency's (DEA) Office of Forensic Sciences and the Office of National Drug Control Policy (ONDCP). The mission of SWGDRUG is to recommend minimum standards for the forensic examination of seized drugs and to seek the international acceptance of these standards [18].

SWGDRUG divided analytical identification techniques into three categories: A, B, and C, based on their respective discrimination power [18]. While categories $A$ and $B$ are recognized as techniques with high discriminating power, category $\mathrm{C}$ comprises techniques with low discriminating power. Category $\mathrm{A}$ includes infrared spectroscopy (IR), mass spectrometry (MS), nuclear magnetic resonance spectroscopy (NMR), Raman spectroscopy, and X-ray diffractometry. Category B includes gas chromatography (GC), microscopic and macroscopic examination (for cannabis only), and thin layer chromatography (TLC). Category C techniques include the color (spot) test, ultraviolet spectroscopy (UV), and immunoassays (NCDOJ paper). In the present study, drug identification of seized materials involved the following techniques: color (spot) tests, UV-vis spectroscopy, macro- and/or microscopic examination (for cannabis), TLC, attenuated total reflectance Fourier transformed infrared (ATR-FTIR) spectroscopy, and GC-MS. These techniques are explained in detail in the following sections.

\section{Color (Spot) Tests}

Color (spot) is the most commonly used presumptive screening test in forensic laboratories. The type of color test used depended on the physical characteristics of the received samples (i.e. color, texture, shape, and smell). Specific instructions and protocols described by Clarke's Analysis of Drugs and Poisons were used for the identification of the illicit drugs [19]. Table 1 shows the color tests most frequently used in the NPL for drug identification and describes their chemical compositions and targets. 
Table 1

Color tests most commonly used at the NPL

\begin{tabular}{|lll|}
\hline $\begin{array}{l}\text { Test } \\
\text { Reagent }\end{array}$ & Composition & Targeted Drugs \\
\hline Marquis & $\begin{array}{l}1 \mathrm{~mL} \text { formaldehyde }(40 \% \mathrm{v} / \mathrm{v}) \text { in } 100 \mathrm{~mL} \\
\text { conc. Sulfuric acid }\end{array}$ & $\begin{array}{l}\text { Opiates (i.e. heroin), amphetamine, and } \\
\text { methamphetamine [19]. }\end{array}$ \\
$\begin{array}{l}\text { Duquenois- } \\
\text { Levine }\end{array}$ & $\begin{array}{l}\text { (1) Add } 2.5 \mathrm{~mL} \text { acetaldehyde and } 2 \mathrm{~g} \text { vanillin } \\
\text { to } 100 \mathrm{~mL} \text { ethanol }(95 \% \mathrm{v} / \mathrm{v})\end{array}$ & $\begin{array}{l}\text { Cannabinoids in cannabis [19]. } \\
\text { (2) Add conc. Hydrochloric acid }\end{array}$ \\
\hline Scott's & $\begin{array}{l}\text { (3) Add chloroform } \\
\text { (1) Cobalt thiocyanate (2\% w/v) diluted 1:1 }\end{array}$ & Cocaine [19]. \\
& $\begin{array}{l}\text { (2) Add conc. Hydrochloric acid } \\
\text { (3) Add chloroform }\end{array}$ & \\
\hline Fast Blue B B & $\begin{array}{l}\text { Fast Blue B salt (diazotized o-dianisidine, 1\% } \\
\text { w/v) }\end{array}$ & Cannabinoids in Cannabis [19]. \\
\hline
\end{tabular}

\section{Macroscopic and Microscopic Examination for Cannabis}

Macroscopic analysis (visual characterization) was used to document different cannabis species, including Cannabis sativa, Cannabis indica, and Cannabis ruderalis. The characterization included plant gross morphology, palmate arrangement, pinnate appearance, the appearance of serrated edges on the leaflets, the buds (seed or seedless), and the presence of fluted stems and/or stalks. The microscopic examination of leafy materials was performed using a stereomicroscope (Stemi DV4, Carl Zeiss, Jena, Germany), equipped with a cold light (Zeiss KL1500 LCD, Jena, Germany). Analysis included the identification of botanical characteristics such as cytolithic hairs (bear claw appearance), elongated hairs on the underside of the leaf, and resin glands (glandular hair).

\section{Thin Layer Chromatography (TLC)}

As mentioned previously, TLC is categorized by SWGDRUG as a category B technique, and it is commonly used in forensic laboratories as a screening technique [18]. TLC can be used to detect a variety of different drugs, including benzodiazepines, barbiturates, amphetamine, methamphetamine, 3,4-

methylenedioxymethamphetamine (MDMA), ketamine, lysergic acid diethylamide (LSD), cocaine opium, heroin, morphine, marijuana, synthetic cannabinoids, and cathinones [20].

TLC was performed on pre-coated aluminum TLC-sheets $(20 \times 20)$, with a $0.25-\mathrm{mm}$ silica gel layer thickness. Solid samples were dissolved in methanol (MeOH; HiPerSolv CHROMANORM, HPLC grade, BDH prolabo) (VWR International, Fonenay-sous-Bois, France) then spotted onto a TLC plate using capillary tubes (Terumo corporation, Tokyo, Japan). Samples were spotted with their respective standards for comparisons. The plates were then transferred into a TLC bath tank, and sample components were separated based on their polarities using mobile phases. The mobile phases were prepared and used 
according to the recommendation of Clarke's Analysis of Drugs and Poisons [19]. Table 2 lists the mobile phases used in the current study as well as those used frequently at the NPL. Other systems were also used at the NPL, but their usage was not as common as those mentioned below. Samples were run in a suitable screening system for an appropriate length of time (1-2 h) and then sprayed with a drug-specific detection solution. Plates were then visualized using a short-wave ultraviolet (UV) light source and the ultraviolet fluorescent indicator ALUGRAM® Xtra SIL G SIL UV254 (Macherey-Nagel Gmbh, Duren, Germany). Rf values were calculated for each sample, for comparison with standards, using the following formula: $\mathrm{Rf}=$ distance of solvent migration $(\mathrm{cm})$ /distance of sample migration $(\mathrm{cm})$. Finally, the obtained Rf values were used to identify the analytes since each drug demonstrates a characteristic Rf value [19].

Table 2

Screening systems most commonly used at NPL

\begin{tabular}{|lll|}
\hline $\begin{array}{l}\text { Screening } \\
\text { Systems }\end{array}$ & Mobile Phase & Detection solution \\
\hline TA & Methanol-strong ammonia solution $(100: 1.5)$ & Acidified iodoplatinated solution \\
\hline TB & $\begin{array}{l}\text { Cyclohexane-toluene-diethylamine } \\
(75: 15: 10)\end{array}$ & Acidified iodoplatinated solution \\
\hline TC & Chloroform-methanol (90:10) & Acidified iodoplatinated solution \\
\hline TI & Toluene (100) & Fast Blue \\
\hline
\end{tabular}

TA, methanol:ammonia system; TB, cyclohexan:toluene:diethylamine; TC, chloroform:methanol; TI, Toluene.

\section{Ultraviolet-visible Spectroscopy (UV-Vis)}

Ultraviolet-visible spectroscopy is a category $\mathrm{C}$ technique used to identify a number of different compounds, including ketamine hydrochloride, cocaine hydrochloride, diazepam, phenobarbital, and barbital [21]. In our laboratory, a Cary 60 UV-Vis spectrophotometer (Agilent Technologies, Santa Clara, CA, USA) was used for these measurements, and the spectra were recorded using the Cary WinUV Scan software (Agilent Technologies, Santa Clara, CA, USA). Samples were first dissolved in methanol prior to being tested by UV-vis; consequently, calibration was performed using methanol. Analytes were identified by comparing the obtained spectra with standard spectra published in Clarke's Analysis of Drugs and Poisons. Identification of a drug was considerably easier if the pills or capsules were received within their manufacturers' packaging, as this provided details of the expected substances with which to compare spectra.

\section{Attenuated Total Reflection-Fourier Transformed Infrared (ATR-FTIR) Spectroscopy}

ATR-FTIR is a highly discriminating method (category A technique) used by the NPL. It is used as a confirmatory method for the detection of a variety of different drugs including benzodiazepines, amphetamine, methamphetamine, MDMA, lysergic acid diethylamide (LSD), cocaine, opium, heroin, morphine, synthetic cannabinoids, and cathinones. Most of the samples that were examined using this 
method in our laboratory are in a solid form. IR spectra were recorded using a Bruker ALPHA spectrometer (Bruker Optics, Ettlingen, Germany) equipped with a PLATINUM-ATR unit (spectral range $4,000-400 \mathrm{~cm}^{-1}$, 16 scans per $\mathrm{cm}^{-1}$, OPUS 7.5. software), the resolution was approximately $2 \mathrm{~cm}^{-1}$ and correction for atmospheric influences using the OPUS software was performed.

\section{Gas Chromatography-Mass Spectrometry (GC-MS)}

GC-MS is the gold standard approach for forensic drug analysis. The method used for GC-MS analysis in this paper was adapted from our previous study [22] and is described in detail below. GC-MS analysis was used exclusively for identification purposes in this study; no quantification was performed.

In order to prepare the samples, approximately $500 \mathrm{mg}$ of vegetal materials or $10 \mathrm{mg}$ of powder were dissolved in $1 \mathrm{~mL}$ of $\mathrm{MeOH}$ in a glass tube and centrifuged for $10 \mathrm{~min}$ at 1,253 $\times \mathrm{g}$ in a Hettich Universal 320 centrifuge (Hettich Zentrifugen, Germany) at $21^{\circ} \mathrm{C}$. Pills were crushed to powder and capsules were opened and emptied to obtain a powder. After a powder was obtained, $10 \mathrm{mg}$ was then dissolved in methanol. After dissolution, $250 \mu \mathrm{L}$ of the supernatant was transferred into GC-vials for GC-MS analysis.

An acid/base extraction into solvent was used for the separation of sympathomimetic alkaloids in khat (Catha edulis Forsk), cathinone, and cathine, as instructed by SWGDRUG [18]. Briefly, $5 \mathrm{~g}$ of plant leaf material was macerated in a plant mill or broken into tiny pieces. Afterward, $10 \mathrm{mg}$ of oxalic acid was added to the plant materials, and the sample was then mixed with $50 \mathrm{~mL}$ of water. The mixture was then sonicated for 15 minutes in an ultrasonic bath (using a Power Sonic 410 device, Hwashin Technology, Korea). The mixture was filtered using a Buchner funnel in order to separate the liquid from the solid plant materials. The alkalinity of the liquid content was adjusted $(\mathrm{pH} \sim 9)$ using saturated sodium bicarbonate (Sigma-Aldrich; St. Louis, MO, USA), and then samples were extracted using $10 \mathrm{~mL}$ aliquots of chloroform. Aliquots were then combined and evaporated to near dryness under a stream of air. Finally, $250 \mu \mathrm{L}$ of the supernatants were then transferred into GC-vials for GC-MS analysis.

GC-MS vials were analyzed in a GC 7693 Gas Chromatograph (Agilent Technologies, Santa Clara, CA, USA) with an autosampler, and mass spectroscopy was performed using a 5977B GC/MSD Mass Selective Detector (Agilent Technologies, Santa Clara, CA, USA). GC-vials, GC-vial lids, and GC-vial inserts were also purchased from Agilent Technologies (Santa Clara, CA, USA). Methanol (MeOH; HiPerSolv CHROMANORM, HPLC grade, BDH prolabo) was used as a solvent for GC-MS analysis, a blank control, prewashing, for washing between the samples, and for post-sample injection washes, and was purchased from VWR International (Fonenay-sous-Bois, France).

The GC-MS parameters were set as reported in the methodology from our previous study [22]. The injection port temperature was set to $250^{\circ} \mathrm{C}$, the splitless injection volume was $0.2 \mu \mathrm{L}$ under a purge flow of helium gas at $3 \mathrm{~mL} / \mathrm{min}$, and the solvent delay was set to $3 \mathrm{~min}$. The wash steps were: four pre-injection washes, four post-injection washes, two sample washes, and six sample pumps. The initial temperature was set to $100^{\circ} \mathrm{C}$ for $4 \mathrm{~min}$. Ramp 1 was set to $10^{\circ} \mathrm{C} / \mathrm{min}$ until reaching $280^{\circ} \mathrm{C}$, where it remained for $2 \mathrm{~min}$. The ${ }^{\circ} \mathrm{C} /$ min rate for Ramp 2 was set to $6{ }^{\circ} \mathrm{C}$ until it reached $300{ }^{\circ} \mathrm{C}$, where it remained for 5 min. An HP-5MS UI column of $30 \mathrm{~m}$ length, $0.25 \mathrm{~mm}$ inner diameter, and $0.25 \mu \mathrm{m}$ film thicknesses (Agilent, Waldbronn, 
Germany) was used with the flow rate set to $1 \mathrm{~mL} / \mathrm{min}$. The MS ionization mode was electron ionization (El) set at - $70 \mathrm{eV}$, with an ion-source temperature of $280^{\circ} \mathrm{C}$ and an interface temperature of $290{ }^{\circ} \mathrm{C}$. Ions were monitored using SCAN mode. Cayman Spectral, FORCHEM, and NIST 14 Libraries were used for comparative analysis.

\section{Toxicology Laboratory Procedures}

One of the job duties of the Forensic Toxicology Laboratory (FTL) in the General Department of Criminal Evidences is to analyze drug metabolites in biological matrices including urine and blood. Each toxicology analysis is then translated into an official report to confirm or deny drug abuse suspension, and to be used for subsequent legal actions. Biological specimens for toxicology testing were collected and submitted by several different governmental agencies including the Forensic Medicine Unit (FMU), the Ministry of Health, the General Staff of the Kuwaiti Army (Medical Services), and the National Guard Medical Services. For quality assurance measures, receipt of these samples by the FTL followed the exact procedures described earlier for the NPL.

In the present study, data for the analyzed and reviewed materials were collected from FTL archives (January 2015-December 2018). Regardless of the toxicological outcome (positive/negative), a total of 17,755 cases were received by the FTL (2015-2018). The numbers per calendar year were; 5,171 in 2015 , 3,708 in $2016,4,115$ in 2017, and 4,761 in 2018. This study only analyzes reports from specimens that yielded positive results for drug abuse. In addition, some positive cases were not reported herein, as the toxicants are irrelevant to the current study. All data were collected with permission from the Ministry of Justice and the Ministry of Interior.

\section{Urine Sample Collection from Deceased Cases}

If available, urine was syringed from the bladder of deceased individuals, using a $10 \mathrm{~mL}$ syringe as soon as they were admitted to the Forensic Medicine Unit (FMU). The specimen was then stored at $20^{\circ} \mathrm{C}$ until analysis. Suspended or hospitalized individuals provided $10 \mathrm{~mL}$ of urine samples in containers, which were sealed and taped to prevent adulteration.

\section{Blood Sample Collection}

Venous blood was taken from a cubital vein by a physician or registered nurse using $10 \mathrm{~mL}$ gray-stopper evacuated glass tubes containing sodium fluoride $(100 \mathrm{mg})$ and potassium oxalate $(25 \mathrm{mg})$ as preservative agents.

\section{Screening of Urine and Blood Samples}

Urine samples were screened by Evidence ${ }^{\circledR}$ Drug of Abuse (DOA) Array I Urine Plus (DOA I URN P) assays (Randox, Crumlin, County Antrim, UK). Evidence ${ }^{\circledR}$ Drug of Abuse (DOA) The Ultra whole blood (DOA ULTRA WB) (Randox, Crumlin, County Antrim, UK) assay was used for semi-quantitative determination of the parent molecule and the metabolites of illicit drugs in human blood. The core technology of the assay depends on a biochip array containing drug-specific antibodies immobilized in predefined regions. These biochips perform simultaneous detection of multiple analytes (up to 20 of the most common) from a 
single biological specimen. To detect and semi-quantify drug in the sample, a competitive chemiluminescence immunoassay was employed with drug labeled with horseradish peroxidase (HRP). Thus, an increase in sample drug concentration will result in increased competition for the antibody binding site and the emitted signal will be reduced. Digital imaging technology (charged coupled device (CCD) camera), is employed to detect the emitted signal, and this is compared against a stored calibration curve to calculate the concentration of the analyte in the sample. The immunoassay cutoff concentrations for each DOA were applied per the recommendations provided in the Randox Guidelines. Each biochip cassette can hold nine individual biochips and the analyzer has a total capacity of four biochip cassettes. The analyzer used was the Randox Evidence immunoassay analyzer (Randox, Crumlin, County Antrim, UK).

The whole blood samples were prepared for application into the biochips by centrifuging $5 \mathrm{~mL}$ of each sample at $1,253 \times g$ in a Hettich Universal 320 centrifuge (Hettich Zentrifugen, Germany) for 10 min and then diluting the sample four-fold ( $150 \mu \mathrm{L}$ sample $+450 \mu \mathrm{L}$ sample diluent) in sample diluent (DOA ULTRA WB DIL SPE) (Randox, Crumlin, County Antrim, UK). Diluted sample was then placed into $16 \mathrm{~mm}$ diameter tubes on the carousel. The urine specimens used are free of contamination and do not contain foreign materials. Therefore, samples were only centrifuged when turbid. Urine samples were stored at a temperature of 15 to $25^{\circ} \mathrm{C}$ prior to testing. The required minimum sample volume for the screening test in test cup/ tube was $500 \mu \mathrm{L}$. Fresh urine samples did not require any pre-treatment as the use of chemical preservatives is not recommended for urine analysis by Randox. Positive samples obtained in a preliminary screening were then extracted and analyzed for confirmation.

\section{Liquid Chromatography with Tandem Mass Spectrometry (LC-MS/MS)}

Details of the LC-MS/MS method and the materials used have been published in detail in our previous publication and are outlined below [22]. Prior to analysis, solid phase extraction (SPE) was used to extract illicit drugs from urine and blood samples for testing. The materials required for LC-MS/MS analysis were obtained as follows: LC-MS grade water was obtained from an ultrapure water system (Sartorius, Bohemia, NY, USA); Borate was obtained from Sigma-Aldrich (St. Louis, MO, USA); Methanol (MeOH; HiPerSolv CHROMANORM, HPLC grade, BDH prolabo) was obtained from VWR International (Fonenaysous-Bois, France); LC-MS grade formic acid was obtained from Honeywell Fluka (Morris Plains, NJ, USA); Acetonitrile was purchased from Honeywell Riedel-de Haën ${ }^{\mathrm{TM}}$ (Muskegon, MI, USA); Vials and lids were purchased from Agilent Technologies (Santa Clara, CA, USA); Standards were purchased from Cayman Chemicals (Ann Arbor, MI, USA), Chiron AS (Trondheim, Norway), and Lipomed (Arlesheim, Switzerland); Surine $^{\text {TM }}$ Negative Urine Control ( $50 \mathrm{~mL}$ ) was purchased from Cerilliant (Round Rock, TX, USA); and Human whole blood used in validation procedures was obtained from Utak Laboratories Inc. (Valencia, CA) and verified to be negative for all target analytes.

CHROMABOND $\circledast \mathrm{C} 18 \mathrm{ec}$ columns with a volume of $3 \mathrm{~mL}$ containing $500 \mathrm{mg}$ sorbent (Macherey-Nagel, Düren, Germany) were used for solid-phase extraction of urine samples. The $\mathrm{pH}$ of the urine samples $(10 \mathrm{~mL})$ were adjusted according to Macherey-Nagel guidelines for specific drugs of abuse and samples were then centrifuged. Columns were set on a glass block vacuum manifold, and a vacuum $(10 \mathrm{mmHg})$ 
was applied to ensure slow dropwise sample flow. For column conditioning, methanol (2 column volumes) was applied, followed by distilled water at $\mathrm{pH} 7$ (2 column volumes). Next, $3 \mathrm{~mL}$ of the pre-treated sample was applied onto the column with slow force and then aspirated. The column was washed with distilled water ( 2 column volumes), and then dried at full vacuum power $(10 \mathrm{mmHg})$ for $10 \mathrm{~min}$. A collection rack containing test tubes was inserted into the manifold for elution of the analytes. The eluent $(750 \mu \mathrm{L})$ was aspirated into the column packing, and the column was incubated for $1 \mathrm{~min}$. The elution step was repeated twice. Although different eluents were used for different drugs as recommended by the column manufacturers, for many of the drugs an eluent of acetone/chloroform (1:1) was used. Subsequently, the SPE eluent was evaporated to dryness at $45^{\circ} \mathrm{C}$ under a gentle stream of nitrogen and the residual was reconstituted in $100 \mathrm{~mL}$ of an equal mixture of methanol and deionized water. The extract was vortexed for $30 \mathrm{~s}$ and then transferred to $200 \mu \mathrm{L}$ inserts held in $2 \mathrm{~mL}$ autosampler vials for LC-MS/MS analysis.

CHROMABOND $®$ Drug Columns with a volume of $3 \mathrm{~mL}$ containing $200 \mathrm{mg}$ sorbent (Macherey-Nagel, Düren, Germany) were used for solid-phase extraction of blood samples. The column was set on a glass block vacuum manifold in preparation for use. For column conditioning, the column was washed with $5 \mathrm{~mL}$ of methanol, followed by $5 \mathrm{~mL}$ of water, and then $5 \mathrm{~mL}$ of borate buffer $(0.05 \mathrm{M}, \mathrm{pH} 8.5)$. Blood or serum $(1 \mathrm{~mL})$ was mixed with $1 \mathrm{~mL}$ of borate buffer $(0.05 \mathrm{M}, \mathrm{pH} 8.5)$, vortexed, and then centrifuged for 5 min at $12,000 \times g$. The pretreated sample was then loaded onto the column. A vacuum $(10 \mathrm{~mm} \mathrm{Hg})$ was applied to ensure a slow drop-wise sample flow. The clear supernatant of the treated sample was aspirated through the column in about $5 \mathrm{~min}$. The column was then washed sequentially with $2 \mathrm{~mL}$ of distilled water, $1 \mathrm{~mL}$ of acetate buffer ( $0.1 \mathrm{M}, \mathrm{pH} 4.0)$, and $2 \mathrm{~mL}$ of methanol. The washed column was dried under full vacuum $(10 \mathrm{~mm} \mathrm{Hg})$ for $10 \mathrm{~min}$. Analytes were then eluted with freshly prepared dichloromethane - isopropanol concentrated ammonia (80:20:2, v/v/v) under gravity. Subsequently, the SPE eluent was evaporated to dryness at $45^{\circ} \mathrm{C}$ under a gentle stream of nitrogen, and the residual was reconstituted in $100 \mathrm{~mL}$ of an equal mixture of methanol and deionized water. The extract was vortexed for $30 \mathrm{~s}$ and then transferred to $200 \mu \mathrm{L}$ inserts held in $2 \mathrm{~mL}$ autosampler vials for LC-MS/MS analysis.

A Q Exactive ${ }^{T M}$ Hybrid Quadrupole-Orbitrap ${ }^{T M}$ Mass Spectrometer (Thermo Fisher Scientific, Bremen, Germany) was used to confirm the results generated from the screening test. The mass spectrometer was a benchtop LC-MS-MS system that combines quadruple precursor ion selection with high-resolution, accurate-mass (HRAM) Orbitrap detection. The settings of the instrument and parameters were used as described in our previous publications with some modifications. Before and after aspiration, the autosampler was rinsed with $1,600 \mathrm{~mL}$ of acetonitrile/isopropyl alcohol/water (45:45:10), containing $0.1 \%$ formic acid. The $Q$ Exactive mass spectrometer was equipped with a heated electrospray ionization source (HESI-II) and was operated in the positive ionization mode. Parameters were optimized according to methodologies taken from the previous study with some modifications [23], including a sheath gas flow rate of 53 , an auxiliary gas flow rate of 14 , and a sweep gas flow rate of 3 (manufacturer units). The spray voltage was set at $3 \mathrm{kV}$, the capillary temperature was set to $269^{\circ} \mathrm{C}$, the auxiliary gas heater temperature was set to $438^{\circ} \mathrm{C}$, and the S-lens RF level was set to 55 . The scan parameters were set as follows: full MS scan with a resolution of 70,000, Automatic Gain Control (AGC) target 1e6, maximum injection time (IT) $100 \mathrm{~ms}$, scan range 100-1,000 m/z, and centroid spectrum data type. For data acquisition, the TraceFinder

Page $11 / 35$ 
4.1 software from Thermo Scientific was used, and the Thermo Scientific ${ }^{\text {TM }}$ Chromeleon $^{\text {TM }}$ Chromatography Data System (CDS) was used to ensure data quality and manage the analytical processes.

Samples $(5 \mathrm{~mL})$ were injected into a $2.6 \mathrm{~mm}$ Accucore $^{\mathrm{Tm}}$ Phenyl-Hexyl column $(100 \times 2.1 \mathrm{~mm})$ and the LC column was heated to $40{ }^{\circ} \mathrm{C}$. Analytes were resolved at $0.5 \mathrm{~mL} / \mathrm{min}$ using a mobile phase consisting of two solvents. Mobile phase A comprised $1 \mathrm{mM}$ ammonium formate and $0.1 \%$ formic acid. Mobile phase $B$ comprised $70 \%$ acetonitrile, $1 \mathrm{mM}$ ammonium formate, and $0.1 \%$ formic acid. Gradient conditions were set as follows: $10 \%$ B for $0.5 \mathrm{~min}$, an increase to $90 \%$ B over $5.5 \mathrm{~min}$, held at $90 \%$ B for $0.9 \mathrm{~min}$, an increase to $98 \%$ B from 7.0 min, held at $98 \%$ B for $2 \mathrm{~min}$, and then column re-equilibration at $10 \%$ B for $1.7 \mathrm{~min}$. At $6.5 \mathrm{~min}$, the flow rate was increased from 0.5 to $1.0 \mathrm{~mL} / \mathrm{min}$ and held for $3.9 \mathrm{~min}$ before returning to the initial rate of $0.5 \mathrm{~mL} / \mathrm{min}$ at $10.6 \mathrm{~min}$. The total run time was $10.7 \mathrm{~min}$.

The compound database used for analysis was the Forensic Database (Forensic DB). However, the identification of the unknown or examined samples by the library database in this step was only tentative. Therefore, reference standards were used following preliminary identification of the unknown sample using the library, and an LC-MS/MS procedure was developed. The LC-MS/MS procedure used in the current study was a two-step scheme that was performed after injecting $10 \mathrm{mg} / \mathrm{mL}$ of the standard in methanol and $100 \mathrm{ng} / \mathrm{mL}$ of the standard in blank urine (for urine samples) or blank blood (for blood samples). The standards were extracted from blank urine or blank blood using the SPE method and used as quality controls. The scheme of the LC-MS/MS procedure includes the following steps. First, multiple reaction monitoring (MRM) was performed to monitor a single transition for each analyte of interest. Second, an information-dependent acquisition (IDA) enhanced product ion scan (EPI) was collected to obtain a full spectrum of the selected compound. The MS spectra were then compared to the library database, and identification of the "unknown" or the samples obtained from the toxicology laboratory was based on quality of fit using the search algorithm in the software, the correct retention time, and visual spectral inspection.

\section{Data Analyses}

Raw data visualization, analysis, and graph creation were conducted using GraphPad Prism version 6 (Prism Software Corporation) and Microsoft Excel 2016 (Microsoft Corporation).

\section{Results}

NPL received a total of 6,220 drug abuse cases from 2015 to 2018 . For analytical purposes, the current study focused on cases with positive drug outcomes: the presence of at least one illicit drug listed in the narcotics or psychotropic substances schedules. We have divided the received materials into two groups: (1) substances that can be weighed and thus reported in grams, including liquid materials (i.e. cannabis oil), powders (i.e. heroin and cocaine), vegetal materials (i.e. marijuana and damiana leaves containing synthetic cannabinoids), and solid blocks (such as cannabis and opium blocks), and (2) substances that can be counted, such as pills and capsules (i.e. tramadol, clonazepam, diazepam and alprazolam). Narcotic substances that were received by the NPL and are scheduled and documented in this report include cocaine, opium, heroin, cannabis, and marijuana (Fig. 1). Psychotropic substances that were 
received by the NPL and scheduled and documented in this report include methamphetamine, synthetic cannabinoids, Khat, and psilocybin mushrooms, which can all be weighed in grams (Fig. 2), and methamphetamine, amphetamine, tramadol, and benzodiazepines (such as clonazepam, diazepam, flunitrazepam, alprazolam, and bromazepam), which can all be counted as pills or capsules (Fig. 3). Photographic images were taken as representative examples for some of the seized substances (Additional file 1).

\section{Quantities of Narcotic Drugs Seized in Kuwait from 2015 to 2018}

Figure 1 shows scheduled and documented raw narcotic substances received by the NPL between 2015 and 2018. These include cocaine, opium, heroin, cannabis, and marijuana. Overall, cocaine was the lowest received illicit raw material, with an initial declining trend (2015-2017) that increased in 2018. The cannabis (CAN) and marijuana (MAR) quantities were the highest among the other narcotic drugs. The quantity of seized marijuana increased in 2016 (compared to 2015), decreased in 2017, and increased again in 2018. The quantity of cannabis peaked in 2017 and then declined. While the quantity of opium $(\mathrm{OPI})$ received to the NPL decreased in the final two years, the quantity of seized heroin (HER) remained constant throughout the four years (Fig. 1). A detailed list of the quantities of the received narcotic drugs (grams) is shown in Additional file 2.

\section{Physical Characteristics of Narcotic Drugs Seized in Kuwait from 2015 to 2018}

While cocaine was received mostly as a white powder (95\% of cases), in a few cases (5\%) it was received in its smokable form (crack cocaine); that is, processed with sodium bicarbonate (baking soda) and water. Heroin was received as a powder with a color that ranges from light to dark brown (and, in very rare cases, off-white). Opium in all cases was received as a sticky black solid block with a distinctive odor. Cannabis was mostly received as blocks of various sizes, and sometimes as "shatter" (concentrated cannabis sheets) or in an edible form (candies, brownies, and cookies). In very rare cases, tetrahydrocannabinol (THC), which is the principle psychoactive constituent of cannabis, was detected in some of the received pills. Marijuana was mostly received in dried plant materials or in herb form, but in very rare cases the two plant types (Cannabis sativa or indica) were received.

\section{Amounts of Psychotropic Substances Seized in Kuwait from 2015 to 2018}

The total quantities of psychotropic substances (grams), including methamphetamine, synthetic cannabinoids, Khat, and psilocybin mushrooms are presented in Fig. 2. For the psychotropic substances, the quantity of methamphetamine (MET) decreased in the first three years and then sharply increased in 2018. Similarly, the quantity of Khat (KHA) showed a relative pattern of decrease and increase. For synthetic cannabinoids (SYN CAN), no data was documented in 2015, and the quantity reported in 2016 was low. This is primarily because these substances were only listed and banned in October 2016. Thus, 
the data stated herein report the seized materials only after the banning legislation. In 2017, the quantity increased dramatically, and then the quantity sharply declined (approximately 800 times) in 2018. Finally, the quantity of psilocybin mushrooms (PSY) seized throughout the four years was very low compared to other psychoactive substances. Although the quantity did increase in 2016, it dropped drastically to almost nothing in the following years (Fig. 2). Additional file 3 shows the exact seized quantities of psychoactive substances (grams).

\section{Physical Characteristics of Psychoactive Substances Seized in Kuwait from 2015 to 2018}

In the vast majority of cases, methamphetamine was received as crystal-like glass fragments or small, shiny, white rocks. In very few cases, seized amphetamine occurred in different colors (pink, light blue, and even dark blue). Methamphetamine was also seized in the form of tablets of different colors and sizes. However, the data shown in Fig. 2 do not include the tablet forms of methamphetamine. Descriptions of the physical characteristics of synthetic cannabinoids have been previously reviewed [22]. Khat usually comes in the form of dried plant materials or herbs, and the detected active stimulating compound in these materials are cathinone and/or cathine. Psilocin and/or psilocybin are the active psychoactive compounds in some mushrooms species (including Psilocybe mexicana and P. cubensis, formerly Stropharia cubensis) that are commonly known as magic mushrooms. NPL obtains these active compounds by extracting them from the mushroom plant except in the very rare cases that they are received as a liquid substance.

\section{Quantities of Psychotropic Tablets Seized in Kuwait from 2015 to 2018}

Figure 3 illustrates the quantities of seized psychoactive pills (number of pills or capsules) in Kuwait from 2015 to 2018. Most of the psychoactive substances are received in the form of pharmaceutical products, pills, or capsules. In 2015, approximately 6,500 methamphetamine (MET) pills were seized. The quantity dropped in the following two years to almost 1,000 pills, though it subsequently increased in 2018 to approximately 10,000 pills. Our data show that there was a high demand for amphetamine (AMP), tramadol (TRA), and clonazepam (CLO) in the drug market in Kuwait during the last four years. The quantity of seized amphetamine (AMP) remained almost the same during the four years of the study, except in 2016, in which the number significantly increased. While the quantities of tramadol, clonazepam, diazepam (DIA), flunitrazepam (FLU), alprazolam (ALP), and bromazepam (BRO) fluctuated, the highest quantity for all, except flunitrazepam, was seized in 2016. In comparison to the other psychoactive pills, FLU and BRO had a very low demand in the Kuwaiti market. Additional file 4 shows the precise quantities of seized psychoactive (pills) in Kuwait from 2015 to 2018.

\section{Shapes and Types of Seized Psychoactive Pills and Capsules in Kuwait from 2015 to 2018}

Methamphetamine was also seized in a small, red tablet form, labelled on each side with a distinctive alphabetical symbol (either $\mathrm{J}$ or $\mathrm{W}$ ). The tablet form of amphetamine had a beige color and was marked with two different characters on each side: $(\nabla \otimes)$ and (-). Rarely, the tablet had a horse-like head shape on 
one side and a character on the other side (-). The benzodiazepine pills seized included diazepam, bromazepam, and clonazepam; these were all pharmaceutically manufactured by Roche Company. The diazepam tablets were blue and beige in color, while the bromazepam and clonazepam tablets were circular in shape with a pinkish or white to pinkish color, respectively. Alprazolam, also known as Xanax, had a pinkish color, while flunitrazepam appeared as an oval, green color pill. Tramadol was seized in two different forms, a tablet form and a capsule. The majority were in tablet form (of different sizes) and were either white or red in color. A capsule form of tramadol (dosage $50 \mathrm{mg}$ ) with a distinctive color pattern (half green and half yellow) was also identified in a few cases.

\section{Forensic Toxicology Laboratory}

The Forensic Toxicology laboratory (FTL) received a total of 17,755 cases during the four-year period (2015-2018). The present study focused on positive test drug cases only. The LC-MS-MS data were obtained from the analysis of biological matrices (blood and urine) of living, or deceased individuals.

\section{Illicit Drug Abusers (Male and Female) in Kuwait from 2015 to 2018}

Our results show that many different narcotic drugs and psychotropic substances were abused. These include methamphetamine (MET), amphetamine (AMP), benzodiazepines (BEN), cannabinoids (CAN), heroin (HER), tramadol (TRA), and cocaine (COC).

Our data shows that methamphetamine was the most abused illicit drug in Kuwait throughout 2015-2018, whereas cocaine had the least number of users. For the remaining illegal drugs, no dramatic changes were observed in terms of the number of abusers. Amphetamine, benzodiazepines, cannabis, and heroin were also highly abused. Generally, the number of male abusers was higher than the number of female abusers for all the illicit drugs. Moreover, the change in the number of abusers was inconsistent, and it fluctuated throughout the four years of study (Fig. 4).

The abovementioned abused substances were found to be abused alongside other combinations of illicit drugs (Fig. 5). For instance, heroin was frequently abused, along with amphetamine, methamphetamine, and benzodiazepines. Cannabis was abused with amphetamine, benzodiazepines, methamphetamine, and heroin. All these abused combinations are shown in Fig. 5. Our four-year analysis shows that some of these combinations of abuse decreased, including heroin and amphetamine, heroin and benzodiazepines, and methamphetamine and cannabis. Consistently, the number of males who abused two substances was in all cases higher than the number of female abusers. More interestingly, some combinations, such as heroin and cannabis and amphetamine and cannabis were rarely (in 2015) or never abused by females (in 2016, 2017 and 2018). Quantitative information for gender-based abusers of one and two illicit drugs are listed in the Additional files 5 and 6 , respectively.

\section{Illicit Drugs (One Substance and Two Substances) Associated with Deaths (Male and Female) in Kuwait from}




\section{5 to 2018}

Biological samples of deceased individuals were received from the Forensic Medicine Unit of the General Department of Criminal Evidence. The Toxicology Laboratory analyzed the samples to check for the presence of illicit drugs (qualitative analysis). No quantitative investigations were conducted in the present study, and thus abused drugs were not necessarily the causative agent for the death. The possibility that the deceased subjects may have received prescribed medication cannot be ignored. Thus, the data reposted herein represent only the number of illicit drugs users. Among the identified illicit drugs in the deceased samples were methamphetamine, amphetamine, cocaine, heroin, benzodiazepines, tramadol, and cannabis. The highest numbers of deaths were associated with benzodiazepine and heroin. Figure 6 shows that in the last three years, there was an increase in the number of deaths related to the abuse of methamphetamine, benzodiazepines, and heroin. The numbers of fatalities associated with the abuse of cocaine and tramadol were lower than any other illicit drugs. Additionally, no female deaths were associated with the illegal abuse of cocaine and tramadol.

In addition, we investigated the deaths associated with the abuse of two different illicit drugs (Fig. 7). Our results showed that the abuse of heroin combined with benzodiazepines and that of heroin combined with methamphetamine were associated with the highest number of deaths. Some combinations were only associated with mortality in some years but not others. Examples of combinations with no influence on mortality include heroin and amphetamine in 2016 and 2017, amphetamine and benzodiazepines in 2018, benzodiazepines and cannabis in 2016, methamphetamine and cannabis in 2016 and 2017, amphetamine and cannabis in 2016 and 2017, and heroin and cannabis in 2016. Furthermore, the number of deceased females that have abused combinations of two different illicit drugs was negligible (Fig. 7). Individual gender-based values of the decedents associated with the misuse of one and two illicit substances are reported in Additional files 7 and 8, respectively.

\section{Mortality Rate Associated with the Use of Illicit drugs in Kuwait from 2015 to 2018}

The potential influence of substance abuse on mortality among drug abusers was assessed by calculating the death rate associated with each misused substance (Fig. 8). The death percentage was high among those who abused heroin and benzodiazepines, whereas it was minimum for those who misused cocaine. The four-year trend increased for the mortality associated with abuse of benzodiazepines and methamphetamine and decreased with the mortality associated with heroin misuse (Fig. 8). Additional files 9 and 10 list the four-year cumulative mortality rates (2014-2018) associated with the abuse of one or two substances, respectively.

\section{Discussion}

Drug misuse is a prevalent long-lasting phenomenon affecting individuals in countries all over the world, and the state of Kuwait is not an exception. Therefore, this study was designed to address issues 
surrounding the abuse of illicit drugs in Kuwait. Our study investigated commonly smuggled types of drugs, the most misused substances based on gender, and mortality associated with abuse of each drug. We found that the most seized substances were cannabis (including marijuana), followed by heroin, opium, and cocaine. Among psychoactive substances, amphetamines (including methamphetamine) were received in large quantities in both powder and pill forms. Other substances seized included benzodiazepines, tramadol, Khat, synthetic cannabinoids, and psilocin. Additionally, amphetamines (including methamphetamine), benzodiazepines, cannabis, and heroin were the most abused substances in Kuwait. Moreover, the study disclosed gender-based differences among abusers, where the misuse of all reported substances among males was much higher than that among females. Finally, we were able to associate fatality rate with the abuse of different illegal drugs, with respect to both gender and the most lethal illicit substance combinations.

\section{Trafficking and Marketing of Illicit Drugs in Kuwait}

The initial objective of our study was to determine the different types of narcotic drugs and psychotropic substances that were seized and consumed in Kuwait from 2015 to 2018. In addition, the study aimed to identify gender-based differences and the mortalities associated with the consumption of these illicit substances. Our analysis reports the different types and quantities of illicit drugs that were seized in Kuwait from 2015 to 2018 (Figs. 1 and 2). The variety of drugs seized is primarily associated with the geographical situation of Kuwait relative to major drug-producing countries, including Afghanistan, Pakistan, Iraq, and Iran [24]. However, the variety of drugs seized may also reflect the rapid financial development of Kuwait; its economic prosperity may have made the country an excellent target for the illicit drugs market. The data revealed annual fluctuations in the quantities of the same seized substances. These variations may be associated with the changes in 1) flow of the illicit drugs from the country of origin; 2) smuggling strategies (methods and routes); and 3) activities of Kuwaiti law enforcement.

Cannabis and marijuana were the most often seized substances among narcotic drugs (i.e., opium, heroin, and cocaine). These data are consistent with the INCB report (2018), which stated that cannabis trafficking into or through Kuwait increased by 233\% from 2016 to 2017 [25]. Many countries neighboring Kuwait produce and traffic cannabis and marijuana to Kuwait through different routes. The relative accessibility of Kuwait for these smuggling operations may explain the increase in cannabis and marijuana seizures. The many different producers, routes, and markets for illicit drugs in the Middle East and North Africa (MENA), including those of the Gulf Countries and Kuwait, have been documented by The European Union Institute for Security Studies [10].

Morocco is most likely to be the origin of cannabis in the Kuwaiti market since it is the principal producer of cannabis resin globally ( 47,000 hectares under cultivation). In addition, cannabis may originate from Lebanon and Afghanistan, which are the main suppliers for cannabis in the MENA market [10]. Afghanistan supplies the gulf countries with many illicit drugs, including opium, heroin, and cannabis; these pass through the Iranian docks of Chabahar and Bandar Abbas. According to the INCB report [25], there are indications that Iraq is becoming a key player for illicit drug cultivation and production, including heroin, opium poppy, and cannabis. This is especially prevalent in the Basra region of Iraq, which borders 
Iran and Kuwait. By late 2014, the number of arrests for drug trafficking and drug use nearly doubled in Basra (compared with that in the period 2011-2014). Large quantities of drugs have since been seized in containers at the Basra port and at border crossings. The INCB report stated that Kuwait had witnessed a substantial increase in cannabis trafficking into or through its territory during this period [25]. Indeed, $653 \mathrm{~kg}$ of cannabis were seized in 2015, and this increased to $970 \mathrm{~kg}$ in 2016.

Another important finding was that low quantities of cocaine were received during the four years of the study (Fig. 2). These findings agree with a previous DEA report, which revealed a weak association between the Arab world and the production or trafficking of cocaine. Nevertheless, there is some evidence for an increase in seizures of cocaine in the Middle East that are destined for distribution in Western Europe. The Kuwaiti market did show noticeable quantities of Khat, and this may have been smuggled from Ethiopia and Yemen. While Ethiopian Khat is smuggled by Ethiopian workers via air routes, Khat from Yemen is smuggled to Kuwait via land routes through the borders with Saudi Arabia. Even though Khat use is uncommon among Kuwaiti locals, there may be some influence from neighboring countries with high Khat consumption, including Yemen, Oman, and Saudi Arabia [26].

The most obvious finding to emerge from our study is that illicit use of amphetamine-type stimulants (ATS), including methamphetamine and amphetamine, is highly prevalent in Kuwait (Figs. 2 and 3 ). The NPL usually receives amphetamine as a component of Captagon pills smuggled in from Iraq. In November 2017, 599 bags of Captagon were seized by law enforcement officers in the Basra region of Iraq, near the Kuwaiti border. This seizure was from what is believed to be one of the most significant smuggling operations in recent years. In addition, ATS precursors are lab-processed in Syria and Lebanon into ATS substances, and these are then transported into Kuwait through Iraq. Our data is consistent with the EUISS November 2017 report [10], which declared that the Gulf countries are facing an amphetamine-type stimulant (ATS) addiction crisis. The report showed that abuse of these stimulants accounted for more than $62 \%$ of the admissions into Saudi rehab facilities. According to the report, the increase in ATS addiction in the MENA area could be attributed to the impact of modernization, and exposure to modern Western cultures and lifestyles.

The illegal use of medically prescribed drugs is a worldwide health concern, and our data confirm that the state of Kuwait is not an exception. Several different psychoactive substances were seized by Kuwaiti law enforcement, including tramadol and drugs of the benzodiazepine family. Our data show that confirmed users of psychoactive substances also tested positive for other illicit drugs (i.e. heroin, cannabis, and methamphetamine). Thus, an assumption can be made that the abuse of these psychoactive drugs was associated with behavioral addictions rather than for medical purposes. These substances were abused for pleasure purposes to induce an altered state of consciousness through modifying the perceptions, feelings, and emotions of the user.

Tramadol is a synthetic opioid analgesic usually prescribed to manage moderate to severe levels of pain. Tramadol misuse is a matter of genuine concern in the Gulf countries, as an overdose is associated with significant morbidity and mortality [6]. The abuse of tramadol in the United Arab Emirates has been previously reported [27]. According to the INCB [25], tramadol is used (non-medically) as a mood enhancer, 
to enhance sexual stamina, or to boost energy during physical activities. However, long-term use of tramadol results in psychological and physical dependence, increasing the risk of overdose [25]. In this study, we showed that large quantities of tramadol have been seized, and it is assumed that these are to be used illegally for non-medical purposes (Fig. 1). Our results show that the quantity seized (in pill form) increased significantly from 40,050 in 2015 to 7,460,319 in 2016, before decreasing in the subsequent years (10,150 in 2017 and 42,213 in 2018). According to these data, tramadol has gained great popularity among abusers and the demand in the Kuwaiti market for this illicit drug is high.

Tranquillizers of the benzodiazepine family were among the most popular substances of abuse seized from the Kuwaiti market. These included clonazepam, diazepam, flunitrazepam, alprazolam, and bromazepam (Fig. 3). Our data showed that the classes of benzodiazepines most commonly seized were clonazepam, diazepam, and alprazolam (Fig. 3). Benzodiazepines slow down bodily functions by enhancing the influence of the inhibitory neurotransmitter $\gamma$-aminobutyric acid (GABA), which interacts with $\mathrm{GABA}_{\mathrm{A}}$ receptors to increase their sedative and anxiolytic actions. A previous survey reported that benzodiazepines were among the drugs most abused by youth in Saudi Arabia [28]. Benzodiazepines can be obtained in Kuwait either as smuggled substances from countries such as Iran, Saudi Arabia, the United Arab Emirates, and Egypt, or through illegal purchase from pharmacies without a prescription (or sometimes with a falsified prescription).

\section{Abuse of Illicit Drugs in Kuwait Compared to Neighboring Countries}

The misuse of intravenous illicit drugs has been reported in all MENA countries. Several studies estimate that the number of individuals that are injecting drugs in the region is $349,500-437,000$. While $96.2 \%$ of abusers were reported to use opioids as their primary drug, $14.2 \%$ were abusing stimulants $[29,30]$. The most commonly misused substances in neighboring countries were heroin (63.9\% in Egypt and Morocco), cannabis (46.2\% in Lebanon, Tunisia, and Morocco), and cocaine (32.8\% in Morocco and Lebanon) [29]. In this study, we investigated the number of illicit drug abusers in Kuwait from 2015 to 2018. Most of the abusers used methamphetamine, cannabis, amphetamine, or heroin. The abuse of benzodiazepine, tramadol, and cocaine was less common (Fig. 4). The use of amphetamine-type stimulants has been well established in the Middle East [31].

The abuse of other types of drugs has also been reported [31, 32], including methylenedioxymethamphetamine (MDMA) (predominantly in Lebanon), methamphetamine (mostly in Iran and Lebanon), and benzodiazepines (in Tunisia). In Egypt, the trend of Tramadol and Tamol use is continually rising [31]. Fenethylline (Captagon), a stimulant co-drug of amphetamine and theophylline, is consistently used in the Arabian Peninsula, specifically among adolescent males in Saudi Arabia [33, 34]. Captagon was reported to be an easily accessible drug that can be obtained by e-commerce via the darknet in the United Arab Emirates, Syria, Iraq, and Turkey [34].

Our study also highlighted gender-based differences among substance abusers (Fig. 4). In general, the number of female abusers was much lower than the number of male abusers (Fig. 4). These differences 
can be explained in part by male dominance in the Kuwaiti culture. In addition, previous studies have shown that males abuse almost all kinds of illicit drugs and that they do so much more than females [17]. This extreme abuse by males increases their chances of a visit to the emergency department and of overdose associated mortality [17]. However, women are just as likely as men to develop a substance use disorder [35]. Moreover, studies suggest that females are more susceptible to craving and relapse, two critical phases of the addiction cycle [36-41].

Some abusers were addicted to combinations of multiple drugs, usually a combination of two substances (Fig. 5), but sometimes more (data not shown). Some combinations were more prevalent in a particular year than others. For instance, while the combination of methamphetamine and cannabis was commonplace in 2015 , the popularity of this mixture decreased dramatically in subsequent years. This finding is consistent with a report that cannabis is the most common secondary illicit substance for methamphetamine users [42]. The number of individuals co-abusing heroin and benzodiazepines remained high throughout the four years. This observation is in agreement with that in a study by Jones et al. reported that co-abuse of opioids and benzodiazepines is ubiquitous worldwide [43]. According to Jones et al., co-abuse of benzodiazepine and opioids is primarily for recreational purposes, to enhance the opioid intoxication or "high" and to enable doses that exceed the therapeutic range [43]. A second explanation for the use of benzodiazepines is self-medication; i.e., the treatment of anxiety, mania, or insomnia.

\section{Mortality Associated with the Abuse of Illicit Drugs in Kuwait from 2015 to 2018}

Globally, overdose is the leading cause of death among people who abuse intravenous illicit drugs. It accounts for $50 \%$ of fatalities among people who inject heroin, exceeding other related diseases [7]. In Europe, drug-related death has been rising for the last five years, and drug overdoses account for the loss of 9,000 individuals [44]. In the United States of America, the 2018 annual surveillance report of drugrelated risks and outcomes announced that drug overdoses were responsible for the deaths of 63,632 individuals [45]. However, robust data regarding overdose associated mortality within the Gulf counties (and Kuwait, in particular) are not available. The risk of drug overdose depends on the nature of the misused substances. For example, opioid-dependent individuals and those who inject opioids are more likely to die from an overdose. In addition, the use of opioids with other central nervous system depressants (such as benzodiazepines) increases the risk factor for opioids overdose. Thus, our current study addresses these issues.

In the current study, we investigated the mortality rates among abusers of methamphetamine, amphetamine, benzodiazepines, cannabis, heroin, tramadol, and cocaine (Figs. 6 and 7). Our data showed that the highest mortality rate was among those who abuse heroin, with overall rising trends in those who abuse heroin, benzodiazepines, and methamphetamine (Fig. 6). In contrast, the mortality among tramadol and cocaine users in Kuwait was insignificant compared with that among the other illicit drugs abusers (Fig. 6). The low mortality among cocaine users may be due to the negligible amount of cocaine available in the Kuwaiti market for illegal substances. Although cannabis overdose is rare, it is still possible under certain circumstances. For example, the risk of cannabis overdose increases when it is abused with other 
substances (polysubstance abuse). A cannabis-alcohol combination is also considered as the most frequently encountered drug mixture implicated in traffic accidents [46]. These drug combinations may significantly increase the levels of THC in the blood.

Our data on mortality among multiple drugs abusers in Kuwait (2015-2018) showed that fatality is highest among those who abused heroin-benzodiazepines combinations. Other combinations associated with significant abuser mortality include cannabis-benzodiazepines and cannabis-amphetamines (including methamphetamine) (Fig. 7). The data reported should be interpreted with caution due to the qualitative nature of the analyses. Thus, our mortality rates do not necessarily implicate illicit substance abuse as the primary cause of death.

\section{Limitations of the Study}

As with the majority of studies, the design of the current study is subject to limitations. The most critical flaw lies in the fact that no quantitative analysis was conducted, and the results reported herein were obtained qualitatively. Consequently, we were unable to generalize from some of the research findings with any confidence, including those of mortality rates among drug abusers. Fatality association with drug overdose cannot be established based on qualitative analysis of the drug profile. Moreover, the possibility that the deceased subject used some of the identified drugs for medical purposes cannot be excluded (in which case these drugs may not be a causative agent for the death). Similarly, no quantitative confirmation was used for reporting drug concentrations in the biological samples obtained from living subjects. Only a simple "positive or negative" result was provided in the final report for confirmation of drug abuse. Thus, further research should be undertaken, including a quantitative approach, to provide a comprehensive analysis of illicit drug abuse. Only then can we tackle the drug misuse crisis in Kuwait and actively promote our society as free of illicit substance addiction. An additional source of weakness is our generalization to drug families during drug abuse analysis of biological samples (without specifying the exact derivative). For example, while the existence of benzodiazepines in the samples may be confirmed, identification of the exact derivative was not performed.

\section{Conclusions}

Our findings suggest that there is a growing need to conduct larger scale studies to implement new strategies, policies, and interventions for positive outcomes in populations affected by illicit drugs.

\section{Abbreviations}

AACC American Association for Clinical Chemistry

AGC Automatic Gain Control

ATS Amphetamine-type stimulant

CCD Charged coupled device 
CDS Chromatography Data System

DEA Drug Enforcement Agency

DOA Drug of Abuse

El Electron ionization

EPI Enhanced product ion

FMU Forensic Medicine Unit

FTL Forensic Toxicology Laboratory

GC Gas chromatography

HRAM High-resolution, accurate-mass

IDA Information-dependent acquisition

MENA Middle East and North Africa

MENAHRA Middle East and North Africa Harm Reduction Association

MRM Multiple reaction monitoring

MS Mass spectrometry

NMR Nuclear magnetic resonance

NPL Narcotics and Psychotropic Laboratory

ONDCP Office of National Drug Control Policy

SPE Solid phase extraction

TLC Thin layer chromatography

UNODC United Nations Office on Drugs and Crime

UV Ultraviolet-visible

\section{Declarations}

\section{Ethics approval and consent to participate}

All data were collected and analyzed with the approval from the Government of Kuwait; Ministry of Justice and Ministry of Interior. 


\section{Consent for publication}

All authors consent to the publication of the manuscript in BMC, should the article be accepted by the Editor-in-chief upon completion

\section{Availability of data and materials}

The authors confirm that the data supporting the findings of this study are available within the article and its supplementary materials.

\section{Competing Interest}

The authors declare that they have no competing interests.

\section{Funding}

This research did not receive any specific grant from funding agencies in the public, commercial, or not-forprofit sectors.

\section{Authors' contributions}

Abdullah Al-Matrouk: Conceptualization, Investigation, Data Curation, Supervision, Writing Original Draft, Review and Editing. Mohammad Al-Hassan: Writing Original Draft, Review and Editing and Formal Analysis. Nema Al-Abkal, Hanan Mohammed and Meshal Haider: Data Curation and Formal Analysis. Dalal Al-Shammeri: Methodology. Haider BoJbarah: Supervision.

\section{Acknowledgements}

We would like to thank all the staff in the Narcotics Department and the Forensic Toxicology Department for all the support they provided in the preparation and finalization of this manuscript. Special thanks to the Research and Development Department for their assistance with paperwork. We would also like to express our gratitude to the Forensic Pathology Division for providing the required data.

\section{References}

1. Babor TF, Caulkins JP, Edwards G, Fischer B, Foxcroft DR, Humphreys K, et al. Drug policy and the public good. Oxford, U.K.: Oxford University Press. 2009:27-9. https://doi.org/10.1093/acprof:oso/9780199557127.001.0001

2. European drug report (2018): trends and development. 2018. https://www.emcdda.europa.eu/system/files/publications/8585/20181816_TDAT18001ENN_PDF.pdf. Accessed 18 March 2020

3. Ritchie H, Roser M. Drug use. 2019. https://ourworldindata.org/drug-use. Accessed 12 February 2020.

4. Gryczynski J, Schwartz RP, O'Grad KE, Restivo L, Mitchell S, Jaffe JH. Understanding patterns of highcost health care use across different substance user groups. Health Aff. 2016;35:9- 
5. Degenhardt L, Charlson F, Ferrari A, Santomaur D, Erskine H, Mantilla-Herrara A, et al. The global burden of disease attributable to alcohol and drug use in 195 countries and territories, 1990-2016: a systematic analysis for the Global Burden of Disease Study 2016. Lancet Psychiatry. 2018;5:9871012.

6. Report of the International Narcotics Control Board for 2013. New York: United Nations. 2013. https://www.incb.org/incb/en/publications/annual-reports/annual-report-2013.html. Accessed 11 March 2020.

7. United Nations Office on Drugs and Crime (UNODC). World Drug Report 2017. Vienna: UNODC. 2017. https://www.unodc.org/wdr2017/field/Booklet_1_EXSUM.pdf Accessed 16 March 2020.

8. de Coning E, Stølsvik G. Combatting organised crime at sea: what role for the United Nations office on drugs and crime. Int J Mar Coast Law. 2013;28:189-204.

9. Al-Shazly F, Tinasti K. Incarceration or mandatory treatment: drug use and the law in the Middle East and North Africa. Int J Drug Policy. 2016;31:172-7.

10. Barzoukas G. Drug trafficking in the MENA: the economics and the politics. EU Institute for Security Studies. 2017. https://www.iss.europa.eu/content/drug-trafficking-mena-\%E2\%80\%93-economics-andpolitics. Accessed 13 January 2020.

11. AlMarri TSK, Oei TPS. Alcohol and substance use in the Arabian Gulf region: a review. Int J Psychol. 2009;44:222-33.

12. Sweileh W M, Zyoud SH, Al-Jabi SW, Sawalha AF. Substance use disorders in Arab countries: research activity and bibliometric analysis. Subst Abuse Treat Prev Policy. 2014;9:33.

13. Bajw HZ, Al-Turki ASA, Dawas AMK, Behbehani MQ, Al-Mutairi AMA, Al-Mahmoud S, et al. Prevalence and factors associated with the use of illicit substances among male university students in Kuwait. Med Princ Pract. 2013;22:458-63.

14. Omu FE, Bader AW, Helen D, Slabeeb S, Safar H, Omu AE. Teenagers' awareness of peers' substance and drug use in Kuwait: J Addict Nurs. 2017;28:55-62.

15. Radovanovic Z, Pilcher CWT, Al-Nakib T, Shihab-Eldeen A. On substance abuse in Kuwait (1992-1997). J Subst Abuse. 2000;12:363-71.

16. Al-Najjar M, Clarke DD. Self-esteem and trait anxiety in relation to drug misuse in Kuwait. Subst Use Misuse. 1996;31:937-43.

17. Wilby KJ, Wilbur K. Cross-national analysis of estimated narcotic utilization for twelve Arabic speaking countries in the Middle East. Saudi Pharm 2017;25:83-7.

18. Scientific Working Group for the Analysis of Seized Drugs (SWGDRUG) Recommendations, 6th Ed., 2011, Part III B [Online], pp.14-6. http://www.swgdrug.org/Documents/SWGDRUG\%20Recommendations\%206.pdf

19. Moffat AC, Osselton MD, Widdop B, Watts J. Clarke's analysis of drugs and poisons: in pharmaceuticals, body fluids and postmortem material. Fourth edition, pp. 471-95. London; U.K.: Pharmaceutical Press, 2011. 
20. Harper L, Powell J, Pijl EM. An overview of forensic drug testing methods and their suitability for harm reduction point-of-care services. Harm Reduct J. 2017;14:52.

21. Li Q, Qiu T, Hao H, Zhou H, Wang T, Zhang Y, et al. Rapid and on-site analysis of illegal drugs on the nano-microscale using a deep ultraviolet-visible reflected optical fiber sensor. 2012;137:1596-603.

22. Al-Matrouk A, Alqallaf M, AIShemmeri A, BoJbarah H. Identification of synthetic cannabinoids that were seized, consumed, or associated with deaths in Kuwait in 2018 using GC-MS and LC-MS-MS analysis. Forensic Sci Int. 2019;303:109960.

23. Concheiro M, Castaneto $M$, Kronstrand R, Huestis M. Simultaneous determination of 40 novel psychoactive stimulants in urine by liquid chromatography-high resolution mass spectrometry and library matching. J Chromatogr A. 2015;1397:32-42.

24. European Monitoring Centre for Drugs and Drug Addiction and Europol. EMCDDA-Europol 2013 annual report on the implementation of Council Decision 2005/387/JHA in accordance with Article 10 of Council Decision 2005/387/JHA on the information exchange, risk assessment and control of new psychoactive substances: implementation reports. Luxembourg: Publications Office, 2013.

25. International Narcotics Control Board. Report of the International Narcotics Control Board for 2017. Vienna: United Nations, 2018. https://www.incb.org/incb/en/publications/annual-reports/annualreport-2017.html. Accessed 21 December 2019.

26. Odenwald M, al'Absi M. Khat use and related addiction, mental health and physical disorders: the need to address a growing risk. East Mediterr Health J. 2017;23:236-44.

27. Alblooshi H, Hulse GK, El Kashef A, Al Hashmi H, Shawky M, Al Ghaferi H, et al. The pattern of substance use disorder in the United Arab Emirates in 2015: results of a national rehabilitation centre cohort study. Subst Abuse Treat Prev Policy. 2016;11:19.

28. Nayyer I. Problems with inpatient drug users in Jeddah. Ann Saudi Med. 2001;21:196-200.

29. Degenhardt L, Peacock A, Colledge S, Leung J, Grebely J, Vickerman P, et al. Global prevalence of injecting drug use and sociodemographic characteristics and prevalence of HIV, HBV, and HCV in people who inject drugs: a multistage systematic review. Lancet Glob Health. 2017;5:e1192-207.

30. Middle East and North Africa Harm Reduction Association (MENAHRA). Multicentre Operational Research on Drug Use and Harm Reduction among People Living with HIV/AIDS in the Middle East and North Africa Region. HIV AIDS Asia Pacific Research Statistical Data Information Resources - AIDS Data Hub, 2017. https://www.aidsdatahub.org/multicentre-operational-research-drug-use-and-harmreduction-among-people-living-hivaids-middle-east. Accessed 23 February 2020.

31. United Nations Office on Drugs and Crime (UNODC). World Drug Report 2018.Vienna: UNODC, 2018. https://www.unodc.org/wdr2018/prelaunch/WDR18_Booklet_1_EXSUM.pdf. Accessed 18 December 2019.

32. Ghiabi M. Maintaining disorder: the micropolitics of drugs policy in Iran. Third World Q. 2018;39:277297.

33. Mehrpour O, Sharifi M, and Zamani N. Tramadol Poisoning. In: Andreazza AC, Scola G, editors. Toxicology studies in cells, drugs and environment. InTech. 2015. doi:10.5772/60439. 
34. Captured by Captagon: A new drug of choice in the Gulf. The Economist 2017 Jul 18. https://www.economist.com/middle-east-and-africa/2017/07/22/a-new-drug-of-choice-in-the-gulf. Accessed 23 February 2020.

35. World Drug Report (2018). United Nations Publication, Sales No. E.18.XI.9. https://www.unodc.org/wdr2018/. Accessed 23 February 2020.

36. Center for Behavioral Health Statistics and Quality. Results from the 2016 national survey on drug use and health: detailed tables. Rockville, MD: Substance Abuse and Mental Health Services Administration, 2017. https://www.samhsa.gov/data/sites/default/files/NSDUH-DetTabs2016/NSDUH-DetTabs-2016.pdf. Accessed 7 February, 2020.

37. Anthony JC, Warner LA, Kessler Comparative epidemiology of dependence on tobacco, alcohol, controlled substances, and inhalants: basic findings from the National Comorbidity Survey. Exp Clin Psychopharmacol. 1994;2:244-68.

38. Robbins SJ, Ehrman RN, Childress A R, O'Brien CP. Comparing levels of cocaine cue reactivity in male and female outpatients. Drug Alcohol Depend. 1999;53:223-

39. Hitschfeld MJ, Schneekloth TD, Ebbert JO, Hall-Flavin DK, Marpyak VM, Abulseoud, OA, et al. Female smokers have the highest alcohol craving in a residential alcoholism treatment cohort. Drug Alcohol Depend. 2015;150:179-

40. Fox HC, Morgan PT, Sinha R. Sex differences in guanfacine effects on drug craving and stress arousal in cocaine-dependent individuals. Neuropsychopharmacology. 2014;39:1527-37.

41. Kennedy AP, Epstein DH, Phillips KA, Preston KL. Sex differences in cocaine/heroin users: drug-use triggers and craving in daily life. Drug Alcohol Depend. 2013;132:29-37.

42. Agrawal A, Neale, MC, Prescott, CA, Kendler KS. Cannabis and other illicit drugs: comorbid use and abuse/dependence in males and females. Behav Genet. 2004;34:217-28.

43. Jones JD, Mogali S, Comer SD. Polydrug abuse: a review of opioid and benzodiazepine combination use. Drug Alcohol Depend. 2012;125:8-18.

44. European monitoring Centre for Drugs and Drug Addiction: European drug report 2019: trends and developments. 2019. http://www.emcdda.europa.eu/publications/edr/trends-developments/2019. Accessed 19 January 2020.

45. Centers for Disease Control and Prevention. Annual surveillance report of drug-related risks and outcomes: United States surveillance special report. Centers for Disease Control and Prevention, U.S. Department of Health and Human Services, 2018. https://www. cdc.gov/drugoverdose/pdf/ pubs/2019-cdc-drug-surveillancereport.pdf. Accessed 21 February 2020.

46. American Association for Clinical Chemistry (AACC). Any dose of alcohol combined with cannabis significantly increases levels of THC in blood. ScienceDaily. ScienceDaily, 2015 May 27. www.sciencedaily.com/releases/2015/05/150527112728.htm. Accessed 7 January 2020.

\section{Figures}




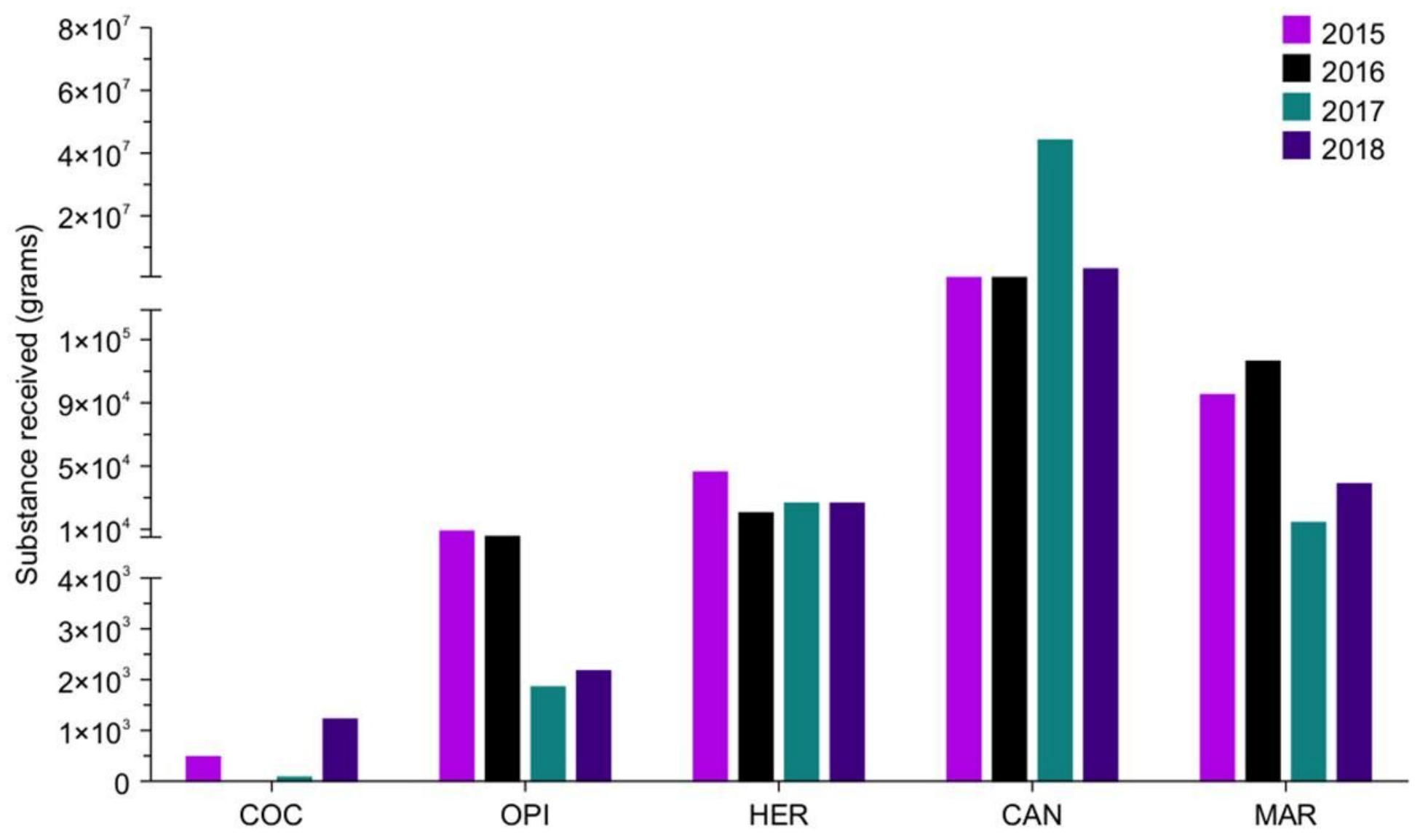

Figure 1

Quantities of different narcotic drugs (grams) received by NPL in Kuwait during 2015-2018; each year is depicted in a different color. COC, cocaine; OPI, opium; HER, heroin; CAN, cannabis; MAR, marijuana 


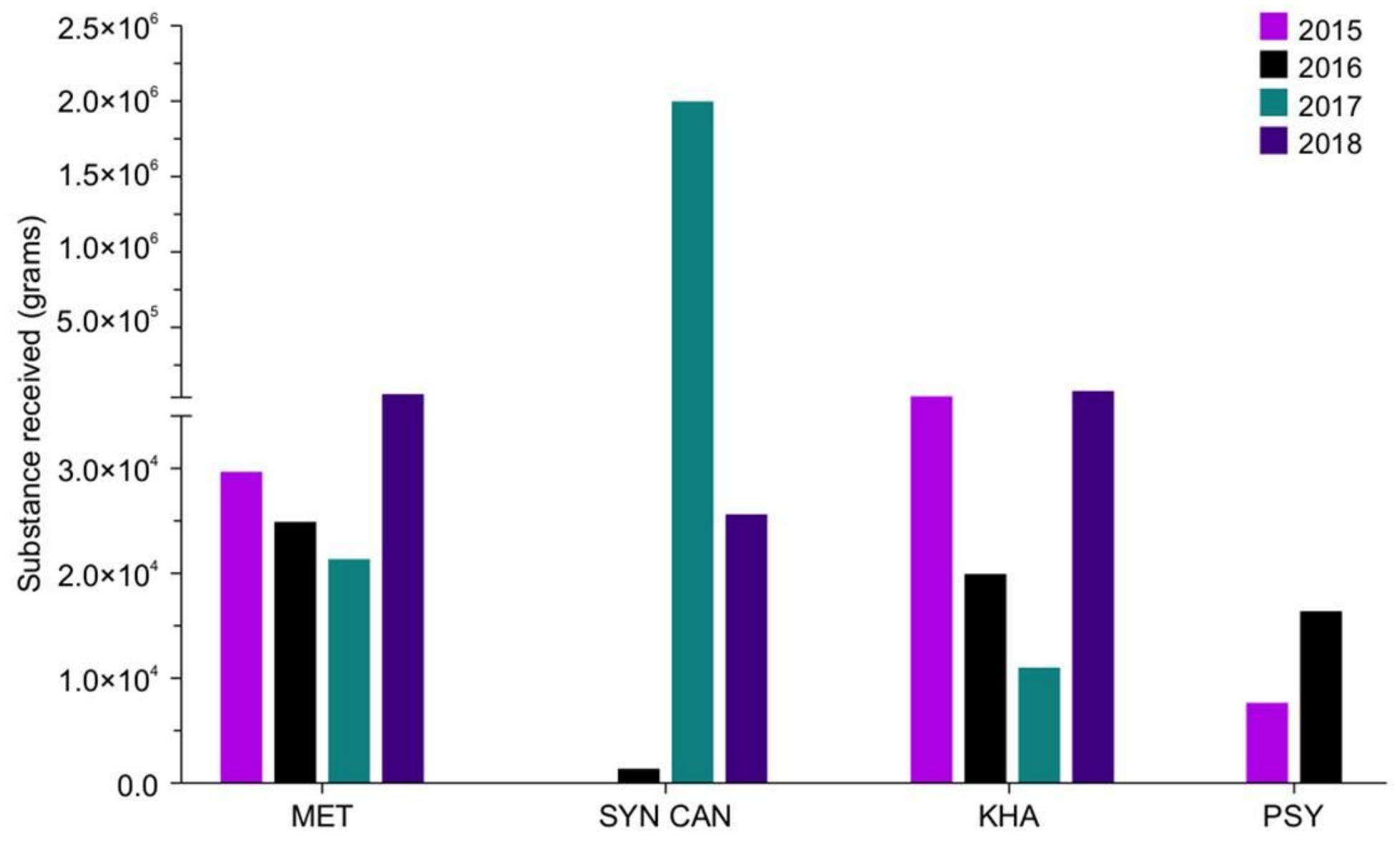

Figure 2

Bar chart showing quantities of psychoactive substances seized in Kuwait during 2015-2018. Each year is depicted in a different color. MET, methamphetamine; SYN CAN, synthetic cannabinoids; KHA, Khat; PSY, psilocybin mushrooms 


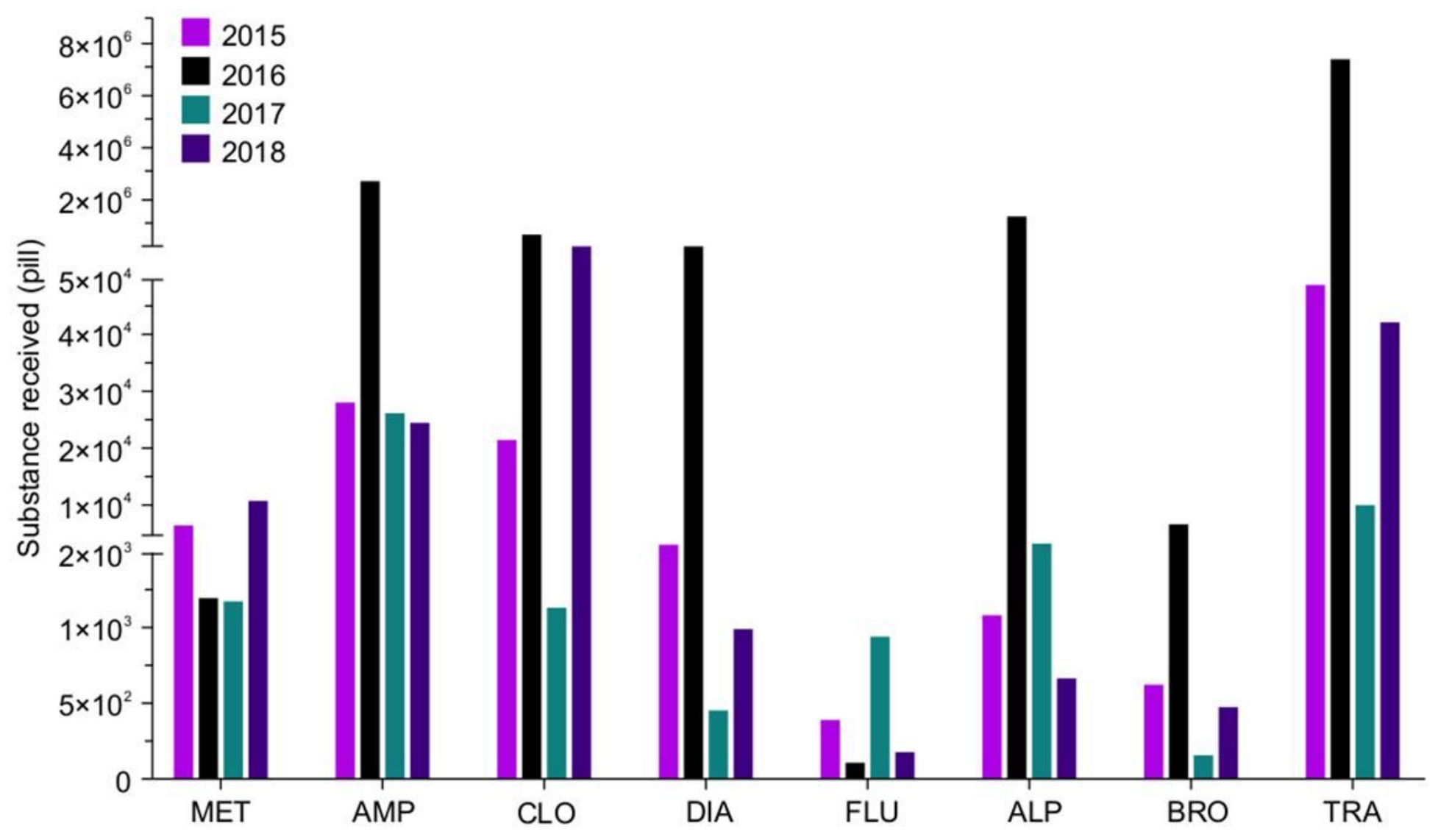

Figure 3

Quantities of seized psychoactive pills (number of pills or capsules) in Kuwait during 2015-2018. Each year is depicted in a different color. MET, Methamphetamine; AMP, Amphetamine; CLO, Clonazepam; DIA, Diazepam; FLU, Flunitrazepam; ALP, Alprazolam; BRO, Bromazepam; TRA, Tramadol. The y-axis is discontinuous at two different points due to the large variation in data 


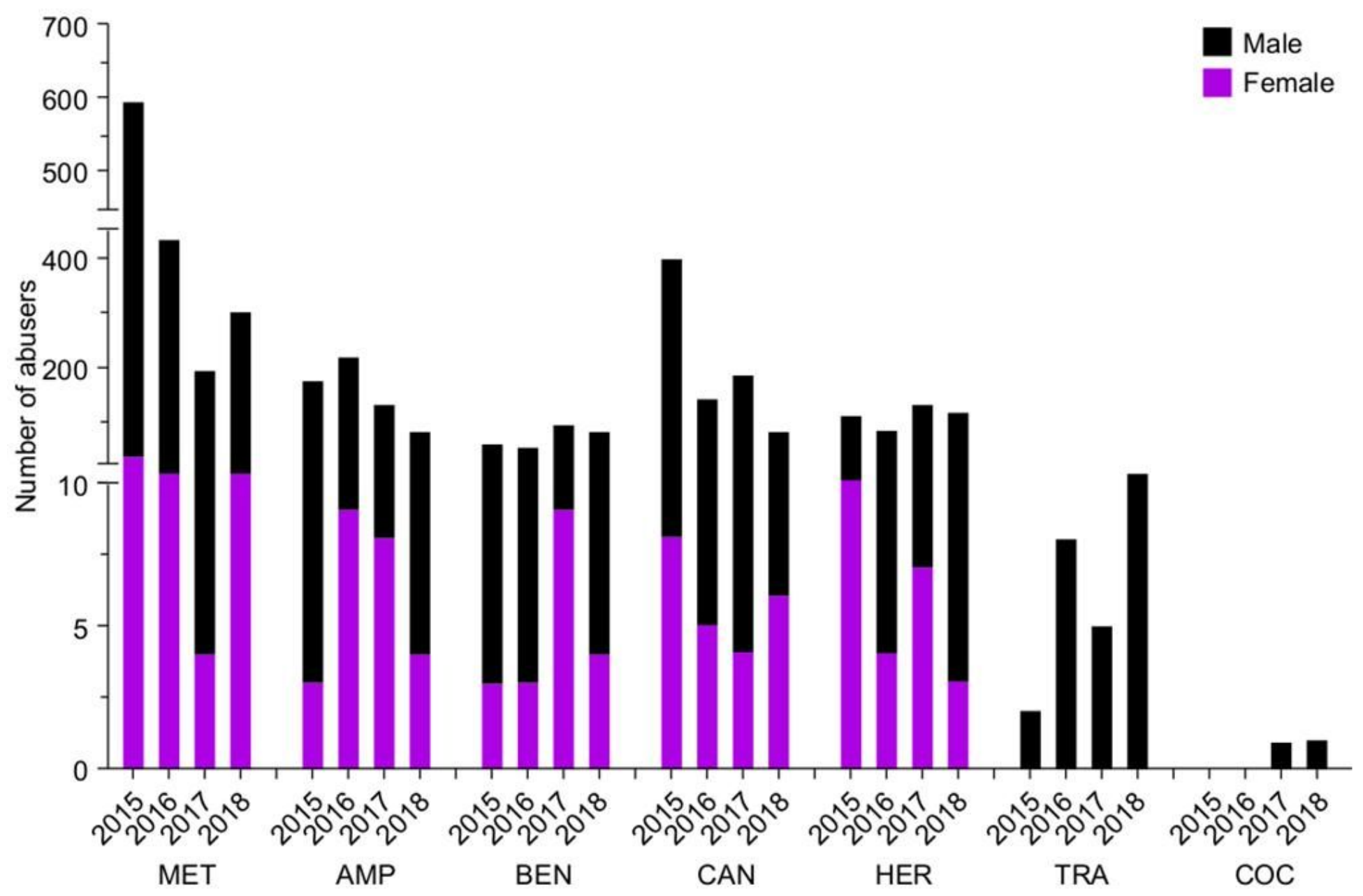

Figure 4

Bar chart showing the number of abusers of different illicit drugs during 2015-2018. Number of male abusers is depicted in black, whereas the number of female abusers is depicted in purple. MET, methamphetamine; AMP, amphetamine; BEN, benzodiazepine; CAN, cannabis; HER, heroin; TRA, tramadol; $\mathrm{COC}$, cocaine. The $\mathrm{y}$-axis is discontinuous at two different points due to the large variation in data 


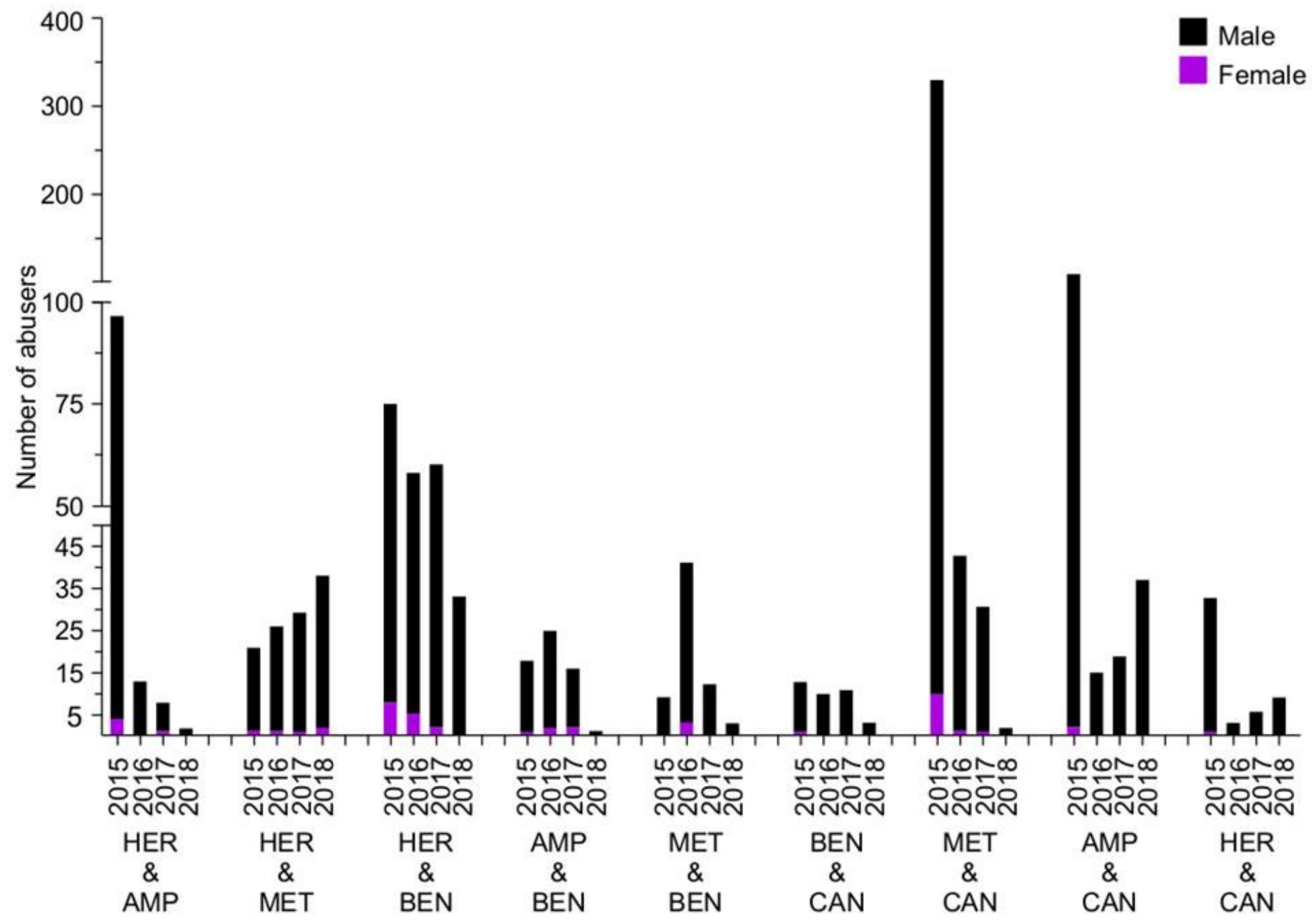

Figure 5

Bar chart showing abusers (number) of two different illicit drugs in Kuwait during 2015-2018. Male and female abusers are distinguished by black and purple colors, respectively. MET, methamphetamine; AMP, amphetamine; BEN, benzodiazepine; CAN, cannabis; HER, heroin. The y-axis is discontinuous at two different points due to the large variation in data 


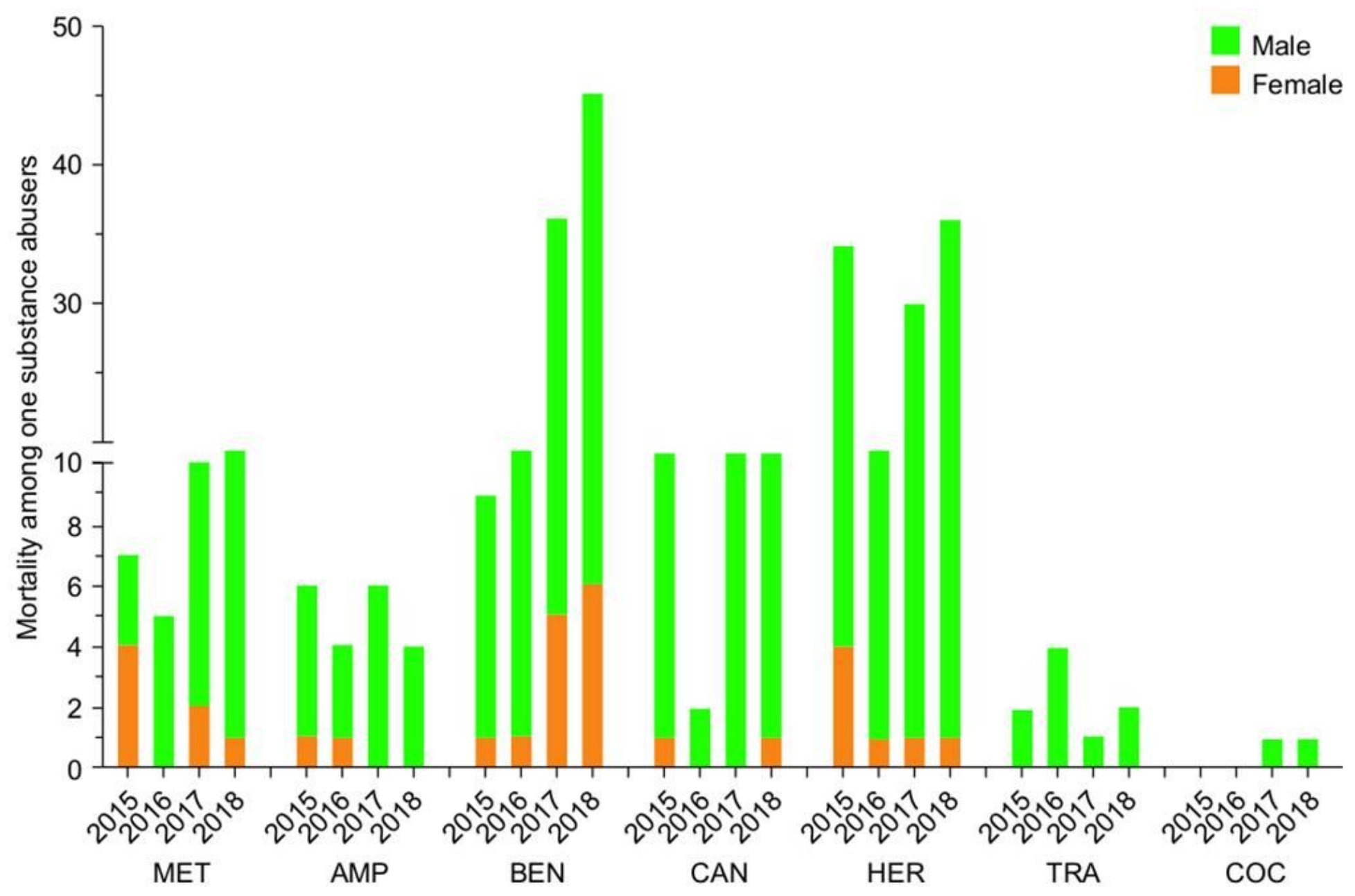

Figure 6

Bar chart showing deceased individuals (number) who were using illicit drugs in Kuwait during 2015-2018. Males and female individuals are differentiated by using different colors (light green for males and orange for females). MET, methamphetamine; AMP, amphetamine; BEN, benzodiazepine; CAN, cannabis; HER, heroin; TRA, tramadol; COC, cocaine. The $y$-axis is discontinuous due to the wide range of data 


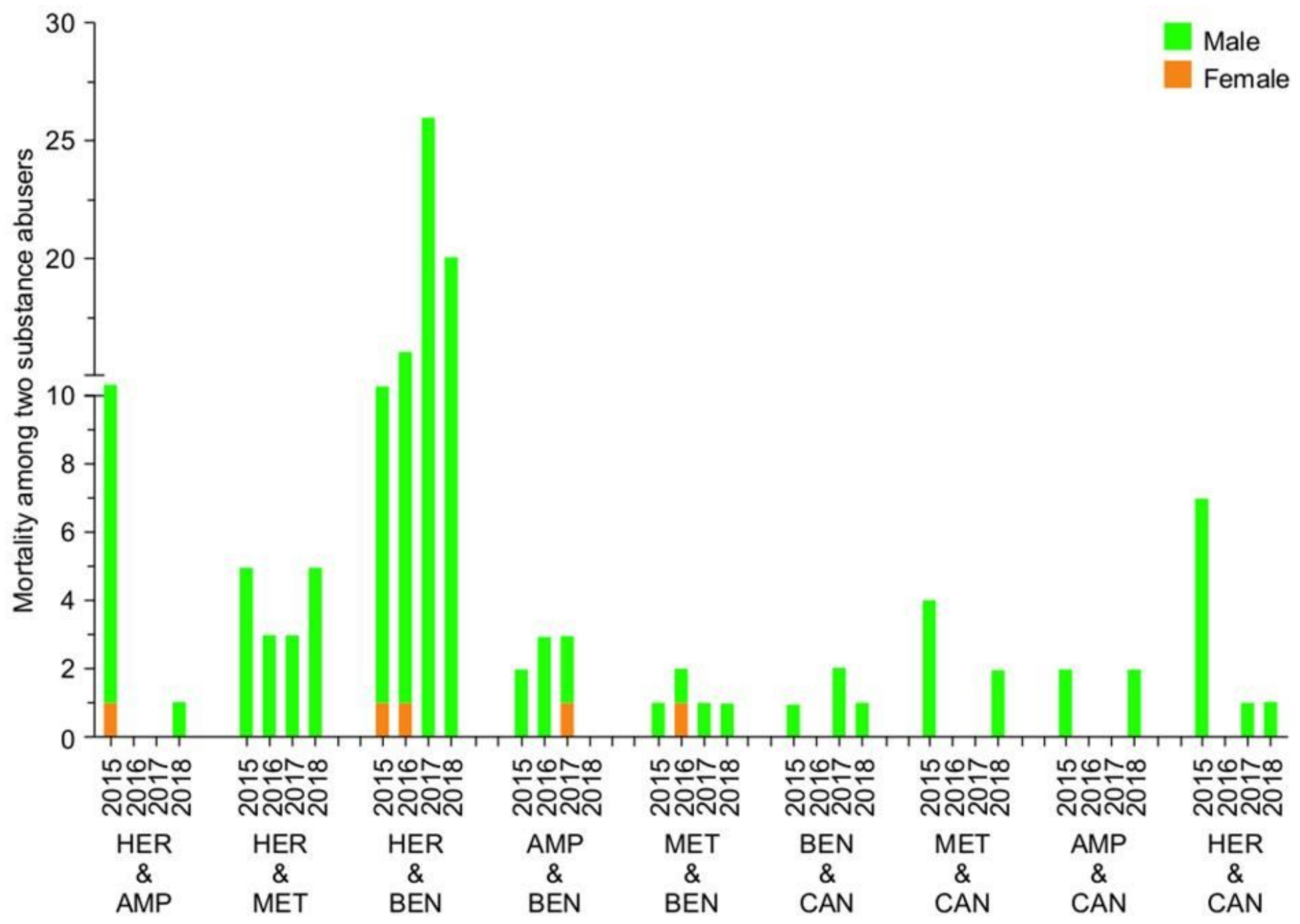

Figure 7

Deceased individuals (number) who were using two illicit drugs in Kuwait during 2015-2018. Males and females were differentiated by using different colors (light green for males and orange for females). MET, methamphetamine; AMP, amphetamine; BEN, benzodiazepine; CAN, cannabis; HER, heroin. The y-axis is discontinuous at one point due to the large variations in the data 


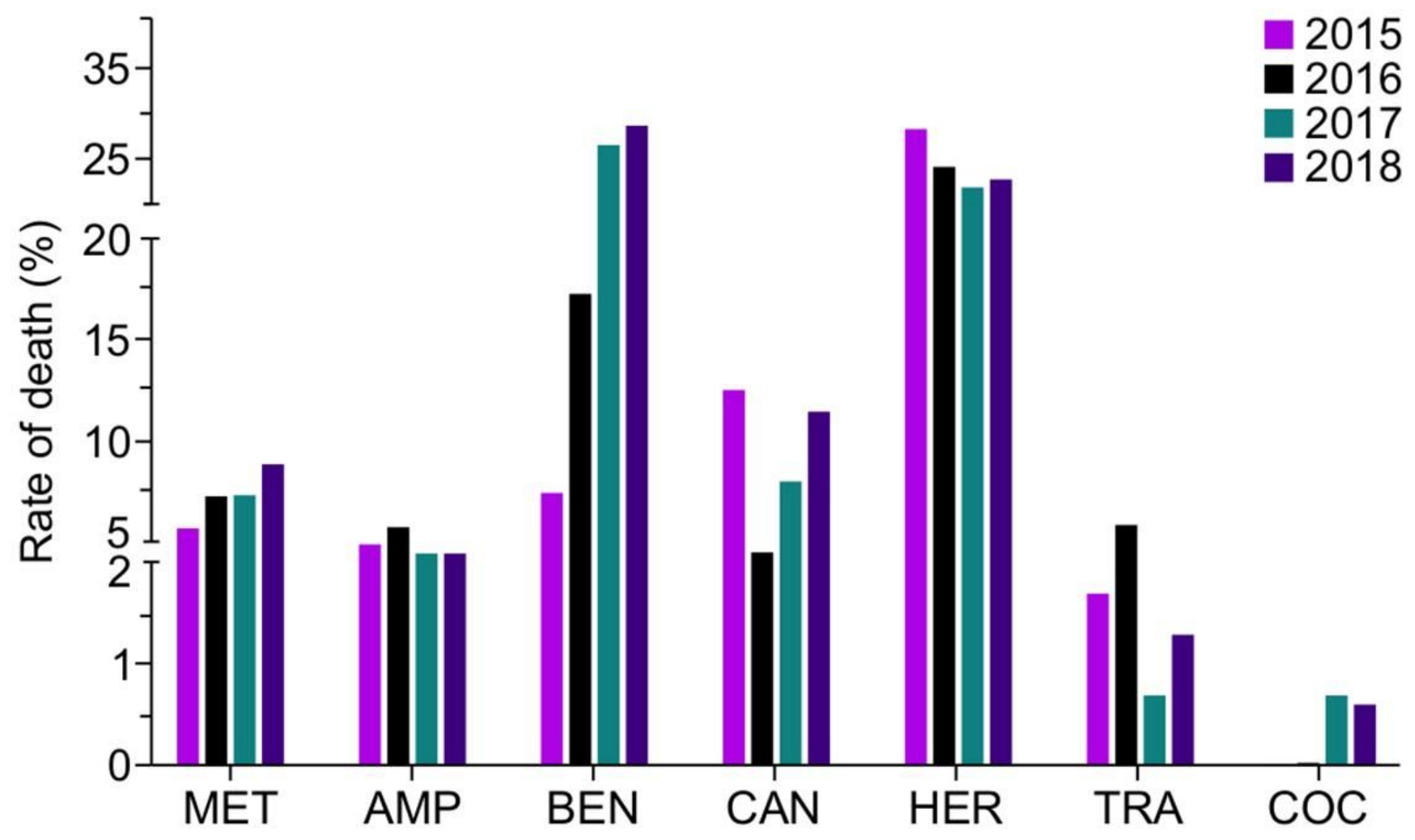

Figure 8

Death rate (percentages) following use or abuse of a particular illicit drug in Kuwait (2015-2018). Each different year is depicted with a different color, as indicated in the legend. MET, methamphetamine; AMP, amphetamine; BEN, benzodiazepine; CAN, cannabis; HER, heroin; TRA, tramadol; COC, cocaine. The y-axis is discontinuous at two different points due to the large variations in data

\section{Supplementary Files}

This is a list of supplementary files associated with this preprint. Click to download.

- supplement12.docx

- supplement13.docx

- supplement14.docx

- supplement15.docx

- supplement16.docx

- supplement17.docx

- supplement18.docx

- supplement19.docx

- supplement20.docx 
- supplement21.docx

Page 35/35 